\title{
PETER SLOTERDIJK: EXPERIMENTOS CON UNO MISMO, ENSAYOS DE INTOXICACIÓN VOLUNTARIA Y CONSTITUCIÓN PSICO-INMUNITARIA DE LA NATURALEZA HUMANA. ${ }^{1}$
}

\author{
Adolfo Vásquez Rocca *
}

Universidad Andrés Bello UNAB - Universidad Complutense de Madrid

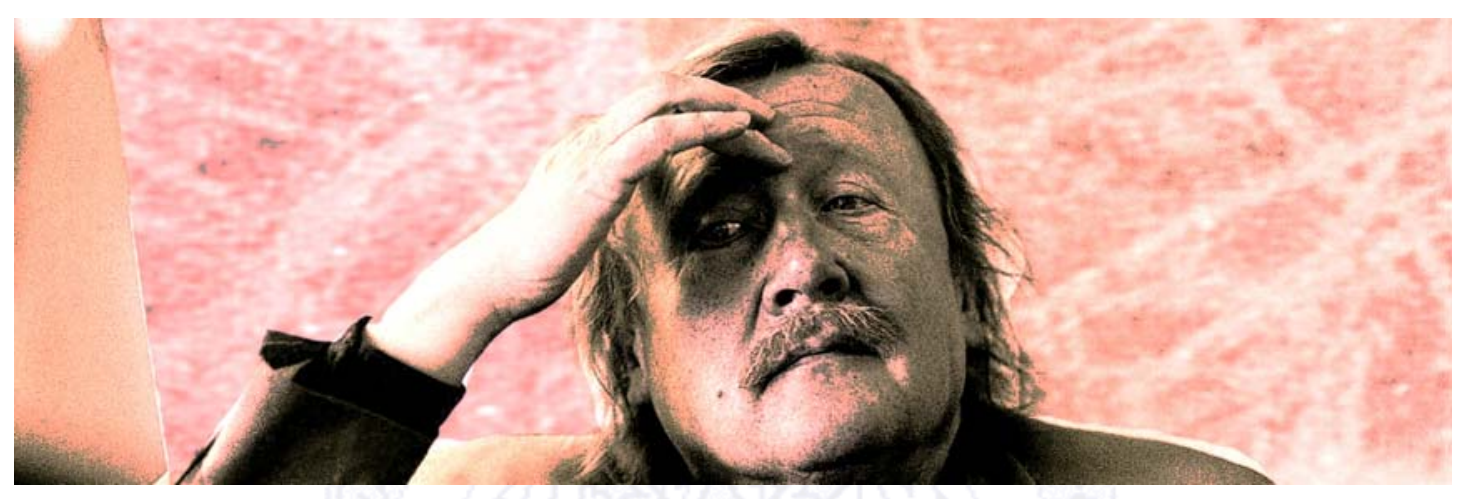

Resumen.- Se indaga en torno a la intoxicación voluntaria, dentro de un programa general encaminado a la experimentación con el propio cuerpo, método que encuentra sus fundamentos en la idea de la medicina romántica donde, según Sloterdijk, los efectos de las dosis en el hombre sano y el enfermo se reflejaban de manera especular. Es aquí donde se origina una ambiciosa semiótica de la medicación farmacológica, no sólo del endomorfinismo de la especulación, sino también de mecanismos endocrinos o quimioéticos.

Sloterdijk se refiere a un proceso de intoxicación voluntaria en referencia al creador de la homeopatía, Samuel Hahnemann, como inventor de una micropolítica de la subjetividad. De la misma manera que el homeópata, según Hahnemann, debe intoxicarse a sí mismo antes de poder dar consejo alguno, el teórico político debe estar dispuesto a arriesgar su identidad en la práctica.

Sloterdijk al referirse a este tipo de "experimentos con uno mismo", no piensa en un experimento de vivisección en las propias carnes, ni tampoco en la psicosis romántica del psicoanálisis, sino que más bien hace referencia, a un fenómeno perteneciente a la historia de la medicina moderna, el movimiento homeopático, que se remonta a hace más de doscientos años y cuya eficacia se

$1 \quad$ Este Artículo -"Peter Sloterdijk: Experimentos con uno mismo, ensayos de intoxicación voluntaria y constitución psico-inmunitaria de la naturaleza humana"- se ha desarrollado en el marco de las Jornadas de preparatorias del Magister en "Biología Cultural", que será dictado por la Escuela Matriztica de Santiago y la Universidad Mayor UM (Santiago) bajo la Dirección del Dr. Humberto Maturana Romesín.

Este Proyecto de investigación-acción se ha gestado en el marco de lo que hemos denominado "ámbito de co-inspiración y colaboración" en la reflexión sobre los fundamentos del vivir y convivir humano desde la perspectiva de la Filosofía, las Ciencias cognitivas y otras disciplinas afines. Este proceso de conversación reflexiva se interroga en torno a preguntas relacionadas con los fundamentos olvidados de lo humano, los mecanismos quimioéticos, la ontogénesis de los espacios humanos de convivencia, así como la constitución de lo patológico. 
verifica en tratamientos terapéuticos -con propuestas médicas adecuadas- capaces de tratar la neurosis moderna. Se examina y discute la convicción heterodoxa de que el médico estaría obligado a intoxicarse a sí mismo con todo lo que él más tarde iba a prescribir a los enfermos. De esta reflexión procede el concepto de experimento con uno mismo: quien quiera ser médico necesita previamente ser cobaya, esto es ser su propio conejillos de Indias.

El autor valioso y útil es el que se contamina él mismo con las materias con las que trabaja, sustancias de alto contenido tóxico, este planteamiento no ha cambiado. Kafka, Musil, Broch, Burroughs todos los grandes del siglo XX, también han sido maestros del pensamiento peligroso.

Palabras clave.- parque humano, intoxicación, inmunología, medicina romántica, biotecnológica, antropotecnias, biopolítica

\section{Peter Sloterdijk: Experiments with oneself, voluntary intoxication tests and psycho- immune constitution of human nature}

Abstract.- We inquire about the poisoning, in a comprehensive program to experiment with one's body, a method that finds its basis in the idea of romantic medicine where, according to Sloterdijk, the dose effects in the healthy and the sick were reflected specular manner. This is where an ambitious originates semiotics of pharmacological medication, not only endomorfinismo of speculation, but quimioéticos endocrine mechanisms.

Sloterdijk refers to a process of voluntary intoxication in reference to the creator of homeopathy, Samuel Hahnemann, as inventor of a micropolitics of subjectivity. In the same way that the homeopath, as Hahnemann himself must intoxicated before giving any advice, political theorist must be willing to risk their identity in practice.

Sloterdijk referring to such "experiments with oneself" and not think of an experiment in vivisection own flesh, nor romantic psychosis in psychoanalysis, but rather refers to a phenomenon belonging to the history of modern medicine, homeopathic movement, which goes back over two hundred years and whose effectiveness is verified with proposed therapeutic-adequate medical treat-able modern neurosis. It examines and discusses the unorthodox belief that the physician would be required to intoxicate himself with all that he was later to prescribe to patients. This reflection should experiment with the concept of self: who wants to be a doctor needs to be guinea pig previously, this is to be your own Indies pigs.

The author is valuable and useful that is contaminated with the materials he works with, high toxic substances, this approach has not changed. Kafka, Musil, Broch, Burroughs all great twentieth century masters are also dangerous thought.

Keywords.- human Park, intoxication, immunology, romantic medicine, biotechnology, anthropotechnics, biopolitics.

"A los pocos que aún rondan los archivos se les impone la idea de que nuestra
vida es la confusa respuesta a preguntas que hemos olvidado donde fueron
planteadas."
Sloterdijk, 1999:46 


\section{1.- Ciencia zoológica y ciencia pneumática: deriva biotecnológica, historia espiritual de la criatura y procesos antropotécnicos.}

En la filosofía de Sloterdijk se puede encontrar una multiplicidad de escenificaciones en las que intervienen los actores por excelencia de la historia: el hombre, la divinidad, los animales, las fuerzas de la naturaleza, los artefactos tecnológicos; todo en escenarios tan dispares como hordas, polis, burbujas, globos, espumas, cosmos; en estados de cosas tan disímiles como el sueño, la vigilia, la subjetividad, el estado narcótico, el líquido amniótico, el jardín del Edén, etc. Ante esto se pueden distinguir dos grandes líneas narrativas que en su filosofía se articulan para dar cuenta de la caducidad del humanismo -la última gran filosofía de la historia- y del advenimiento de una nueva era posthumanista, desestructurando los supuestos fundamentales del humanismo, a saber: la estricta distinción entre naturaleza y cultura; y la dicotomía sujeto y objeto, diversificando los planteamientos y unidades de sentido histórico. ${ }^{2}$ Para esto, Sloterdijk realiza una suerte de historia natural de la especie junto a una historia espiritual de la criatura, relatos que se fundamentan en la tesis nietzscheana según la cual el hombre es un efecto de programaciones y adiestramientos. Así, ciencia zoológica y ciencia pneumática se constituyen en la historia de los procesos antropotécnicos capaz de introducir en la escena de la teoría aquello con lo que el hombre convive -y ha convivido- cotidianamente, a saber: signos, señales, símbolos, máquinas, herramientas, animales, plantas, virus, bacterias, textos, obras de arte, museos, prótesis, intervenciones quirúrgicas, fármacos; a esto se debe sumar la irrupción de los artefactos tecnológicos en la determinación de la vida humana. La historia de esta cohabitación con elementos cuyo estatuto ontológico no ha sido suficientemente aclarado es el desafío de la misma filosofía de Sloterdijk. Bajo esta perspectiva, el mismo estatuto ontológico del hombre no está claro; en este sentido, Sloterdijk entiende al hombre como una deriva biotecnológica asubjetiva que vive hoy -con la invención de la inteligencia artificial y el descubrimiento del genoma humano- un momento decisivo en términos de política de la especie. ${ }^{3}$

En este sentido, se hace necesario desarrollar un pensamiento ecológico que supere el dualismo entre lo natural y lo artificial propio de la concepción humanista del mundo, ciega ante la unidad casi indistinta de un único entorno natural y tecnológico. Así, pues, una ecología filosófica vendría a constituir, en grandes escalas, una nueva cosmología, que consistiría en estudiar las relaciones de las diversas entidades en el escenario del cosmos a partir de criterios polivalentes. De

2 VÁSQUEZ ROCCA, Adolfo, "Sloterdijk y el hombre como experimento sonoro; deriva biotecnológica e historia espiritual de la criatura", En Revista Observaciones Filosóficas - ISSN 0718-3712 - No 4, 2007, Asociada al Postgrado en Filosofía - PUCV y al Grupo THEORIA Proyecto europeo de Investigaciones de Postgrado.

$<$ http://www.observacionesfilosoficas.net/sloterdijkyelhombre.html>

3 VÁSQUEZ ROCCA, Adolfo, "Peter Sloterdijk y Nietzsche; De las antropotecnias al discurso del posthumanismo y el advenimiento del super-hombre", En Psikeba Revista de Psicoanálisis y Estudios Culturales, Buenos Aires No 3, 2006. <http://www.doaj.org/doaj?func=abstract\&id=213239> 
este modo, "si se remontara la creciente complejidad del mundo actual, el cosmos pasaría a ser el ámbito para la conformación de una multiplicidad de nuevos espacios habitables, que fundarían ante todo una nueva política de la cohabitabilidad entre entidades separadas antes por la supuesta pureza o impureza de su naturaleza: entre hombres y maquinas". ${ }^{4}$

Sin embargo, costará remontar niveles tan altos de complejidad. El mundo como hábitat de la especie humana se presenta hoy bajo la forma de una hiperesfera conectada en red. La misma necesidad de anteponer la palabra "hiper" a una serie de conceptos revela que éstos son tiempos exacerbados, a saber: la edad del paroxismo de la complejidad. Ante este estado de cosas nisiquiera el "hiper" da basto para describir en una medida adecuada la actual forma del mundo. Con todo, se requiere una hiperpolítica a la altura de un mundo hipercomplejo ante la presencia de huérfanas multitudes de individuos sin un horizonte de cosas en común más que el éxito personal.

Para Sloterdijk, el gran relato sobre lo que quisiera denominar aquí, a modo de título del texto primario de la época, "Hombres yuxtapuestos o la orfandad del género humano", se sitúa en el reconocimiento cómico y dramático del actual estatuto híbrido del hombre como espécimen biocultural. Habrá que dar cuenta de la unidad de la evolución humana desde sus escenificados orígenes. Para ello, Sloterdijk elabora su ensayo sobre lo que él denomina hiperpolítica, con el fin de mostrar claramente el suceso antropológico fundamental: la creación del hombre por parte del hombre. Un relato en el que intervienen Heidegger y Sloterdijk como dos mentalidades confrontadas en una radical ruptura entre épocas. ${ }^{5}$

\section{2.- Normas y disturbios en el Parque Humano o la crisis del humanismo como utopía y escuela de domesticación.}

Con ocasión de un seminario a los pocos años de la muerte de Levinas, Peter Sloterdijk, profesor de la Universidad de Karlsruhe (en la Hochschule für Gestaltung de Karlsruhe), expuso un documento que llamó el 'Normas para el Parque Humano, una respuesta a la Carta sobre el Humanismo' ${ }^{6}$ suscitando uno de los debates filosóficos más importantes de la actualidad. La referida conferencia tuvo lugar el 17 de julio de 1999 en el castillo de Elmau, en Baviera, con motivo del Simposio Internacional "Jenseits des Seins / Exodus from Being / Philosophie nach Heidegger", en el marco de un ciclo de encuentros sobre "La

\footnotetext{
$4 \quad$ VÁSQUEZ ROCCA, Adolfo, "Sloterdijk, Agamben y Nietzsche: Biopolítica, posthumanismo y Biopoder" En NÓMADAS, Revista Crítica de Ciencias Sociales y Jurídicas - Universidad Complutense de Madrid, No 23 | Julio-Diciembre.2009 (I) pp. 291-302 <http://www.ucm.es/info/nomadas/23/avrocca.pdf> 5 Ibid.

$6 \quad$ SLOTERDIJK, Peter, Normas para el parque humano, Ediciones Siruela, Madrid, 2000. I Conferencia pronunciada en el Castillo de Elmau, Baviera, en julio de 1999 y publicada en Die Zeit ese mismo año.
} 
filosofía en el final del siglo“. La versión inicial de la exposición de Sloterdijk había sido presentada el 15 de junio de 1997, en Basilea, en un encuentro sobre la actualidad del humanismo. El texto fue publicado en su forma definitiva por Die Zeit el 10 de septiembre de 1999.

En esta ponencia Sloterdijk reclama una revisión genético-técnica de la humanidad. En su planteamiento constata que "las fantasías de selección biopolítica han tomado el relevo de las utopías de justicia", de allí que Sloterdijk al destacar los medios y posibilidades que ofrece la biotecnología, sugiera formular un 'código antropotécnico', dejando abierta la posibilidad a una 'antropotecnología' en la que pueda cambiarse el 'fatalismo del nacimiento' por un 'nacimiento opcional' y una 'selección prenatal'. Reviviendo con ello los fantasmas de los totalitarismos del siglo $X X$, con sus sueños eugenésicos y ambiciones de poder y control en la selección de seres humanos. Esta nueva ingeniería social busca cimentarse en una antropología de cuño neo-darwinista, compatible con cualquier racismo revivido, encontrando sus primeros antecedentes en Platón donde los discursos educativos sobre la comunidad humana parecen apuntar a un parque zoológico. ${ }^{7}$

El Humanismo como palabra y proyecto tiene siempre un opuesto, la Barbarie. Es fácil de entender que precisamente aquellas épocas que han hecho sus principales experiencias a partir de un potencial de barbarie liberado excesivamente en las relaciones interhumanas, sean asimismo aquellas en las que el llamado al Humanismo suele sonar más alto y perentorio. Quien hoy se pregunta por el futuro del humanitarismo y de los medios de humanización, quiere saber en el fondo si quedan esperanzas de dominar las tendencias actuales que apuntan a la caída en el salvajismo [Verwilderung] del hombre.

Ahora bien, como lo indica su título, Normas para el Parque Humano aborda el problema del Humanismo bajo la forma de una respuesta al conocido texto de Heidegger de $1946^{8}$. La tesis fundamental es que el supuesto componente bestial de la naturaleza humana quiso ser neutralizado por el humanismo clásico mediante la domesticación a través de la lectura, entendida ésta más que como una campaña de alfabetización, como un masivo envío postal - bajo la forma de extensas cartas dirigidas a los amigos- cartas destinadas a instaurar lo que Sloterdijk define como una sociedad pacificada de lecto-amigos. De tal modo que

\footnotetext{
7 VÁSQUEZ ROCCA, Adolfo, "Peter Sloterdijk: Normas y disturbios en el Parque Humano o la crisis del humanismo como utopía y escuela de domesticación", En UNIVERSITAS @ Revista de Filosofía, Derecho y Política, No 8, 2008, pp. 105-119. Universidad Carlos III de Madrid. <http://universitas.idhbc.es/n08/08-06.pdf>

$8 \quad$ Según, Rüdiger Safranski, cuando en la Carta sobre el humanismo, escrita en 1946, Heidegger reflexiona sobre el pensamiento, su situación personal es la de un proscrito. En la casa de Friburgo se sentía oprimido, tanto por el alejamiento de la universidad, como por el estar pendiente del regreso de los dos hijos, que todavía se hallaban cautivos en Rusia. Sin embargo, a pesar de las circunstancias oprimentes, el filosofar de Heidegger mantiene la actitud fundamental serena de los últimos años de la guerra. Se reviste de la función del "sabio de la montaña", que describe el abuso de la modernidad en grandes perspectivas y panoramas, pensando juntamente en los crímenes del nacionalsocialismo, pero sin reflexionar explícitamente sobre ellos. refugiándose en las ideas "absolutas" de pueblo, caudillo, raza, misión histórica. [En la excelente biografía -Un maestro de Alemania: Martin Heidegger y su tiempo- Tusquets Editores, 2003]
} 
las naciones lejanas serían ellas mismas productos literarios y postales: ficciones de un destino de amistad con compatriotas remotos y una afinidad empática entre lectores de los mismos autores de propiedad común ${ }^{9}$. De ahí en adelante, los pueblos se organizan como ligas alfabetizadas de amistad compulsiva, conjuradas en torno a un canon de lectura asociado en cada caso con un espacio nacional. Esto fue así, hasta el advenimiento de las ideologías, con los Estados- nacionales en los siglos XIX y $\mathrm{XX}$, el humanismo se vuelve pragmático y programático, el modelo de sociedad literaria amplía su alcance, convirtiéndose en norma de la sociedad política y -en la práctica- germen de ambiciones imperialistas. Además de los autores europeos antiguos se movilizan ahora también -para estos fines- clásicos modernos y nacionales, cuyas cartas al público son ensalzadas y convertidas en motivos eficientes de la creación nacional por parte del mercado de libros, las casas de altos estudios y los ideólogos de los nuevos totalitarismos.

¿Qué son las naciones modernas sino poderosas ficciones de públicos letrados, convertidos a partir de los mismos escritos en armónicas alianzas de amistad? Si Nosotros existimos en nuestro origen -en nuestras ficciones fundacionales-, nuestro origen es nuestro lugar espiritual, nuestra radical cultura originaria, de allí que quepa preguntar "si la verdadera Alemania no está en los genes ni en los mapas, sino en las ficciones mediante las cuales se pretende dar lugar a un pueblo, ¿por qué hemos de considerar más autentica la ficción de Hölderlin que la de Hitler?"10

Esta respuesta, nos instala en el problema político del imaginario nacional. En esto consiste el sentido profundo de la propaganda y la sociología de masas -a la que se referirá Sloterdijk en El Desprecio de las Masas ${ }^{11}$ - ante la cual sucumbió el pueblo alemán durante los años trágicos del nacionalsocialismo.

La instrucción militar obligatoria para los varones y la lectura obligatoria de los clásicos para jóvenes de ambos sexos caracterizan a la burguesía clásica, definen a aquella época de humanitarismo armado y erudito, hacia el que vuelven la mirada hoy conservadores de viejo y nuevo cuño, nostálgicos de prácticas prusianas, aunque de seguro no del todo conscientes de llegar a una

$9 \quad$ Con el Renacimiento y la Modernidad, el libro se convirtió en una especie de "carta" dirigida a todos y cualquiera ("el curioso lector"), pero escrita en un determinado idioma, lo cual coincidió con el establecimiento de los Estados nacionales, dando a estos un impulso formidable a partir de la Revolución francesa y la difusión de periódicos y revistas, así como de la enseñanza obligatoria, imponiendo textos de contenido controlado y supervisado, de modo que inculcaran en los estudiantes el "espíritu de la patria". Ahora bien, tras la revolución "mediática" concomitante con las dos guerras mundiales y triunfante justamente tras el fracaso de la última gran revolución: la soviética, el humanismo -el humanismo tipográfico, diríamos- ha entrado en una crisis irremediable. Ya no es válido para el adoctrinamiento ni para la cohesión social. Hasta aquí llega Sloterdijk, dejando a un lado, como oyeron ustedes, una volátil alusión a la necesidad de un Codex de técnicas antropógenas: por cierto, lo único que justificaría el llamativo título, ya que en ninguna otra parte se nos habla de las normas, el estatuto o las reglas del zoo humano.

10 PARDO, José Luis, "A cualquier cosa llaman arte; Ensayo sobre la falta de lugares", en Habitantes de Babel; políticas y poéticas de la diferencia, Ed. Laertes, 2001, Barcelona.

11 SLOTERDIJK, Peter, El Desprecio de las Masas, Editorial Pre-textos, Valencia, 2002, pp. $19-29$. 
comprensión teórica del sentido y alcance de la forja de un canon de lectura... Para darse una idea clara de este fenómeno, basta con recordar el resultado lastimoso de un debate nacional llevado adelante en Alemania -debate inducido sobre todo por los jóvenes- sobre la supuesta necesidad de un nuevo canon literario. Así los Estados nacionales del siglo XIX habrían sido fruto y cristalización final de este proyecto domesticador de impronta metafísica: la época de estos "Nacional-humanismos" se extiende para Sloterdijk entre 1789 y 1945.

La carta de Heidegger es, como se ha visto, contemporánea del período en que termina para Sloterdijk, catastróficamente, la era de la domesticación ilustrada (es un dato importante y sin duda polémico el que el fascismo constituya paradójicamente desde esta perspectiva un producto de la llustración, constituyendo así uno de los rostros que adopta el humanismo ${ }^{12}$ y sus discursos a la vez humanitarios y malintencionados en el siglo $X X$; los otros serían el 'americanismo' y el 'bolchevismo'). Como producto y negación de aquella catástrofe, los años que siguen a 1945 alumbrarían respectivamente el establecimiento definitivo de una industria del entretenimiento desinhibidor y una reacción humanista basada en tres ejes fundamentales (cristianismo existencialismo y marxismo) que da lugar a una restauración de corto plazo y supuestamente sin esperanza del ideal letrado-ilustrado.

La era del humanismo moderno como modelo escolar y educativo ha sido -como se ve- largamente superado, volviéndose insostenible la ilusión de que masivas estructuras políticas y económicas pueden ser ya organizadas siguiendo el modelo amigable de la sociedad literaria.

El fin del humanismo no será ciertamente el fin del mundo, pero sí el de nuestro mundo, el de quienes hemos cifrado nuestras expectativas de progreso humano en el desarrollo de la sensibilidad a través del progreso humanístico-literario como vehículo comunicativo y empático de la experiencia ética, que según nuestro convencimiento nos permitiría superar el etnocentrismo y tener amigos a distancia. Amigos de letra presente.

Hasta la llegada del corto período en que se produjo la alfabetización general, la cultura escrituraria misma mostró agudos efectos selectivos. Hendió profundamente a las sociedades de sus dueños, y abrió una grieta entre literatos y hombres iletrados, cuya infranqueabilidad casi alcanzó la rigidez de una diferencia

12 "Heidegger presenta, en efecto, al mundo histórico de Europa como el teatro del humanismo militante, como el campo sobre el que la subjetividad humana realiza la toma del poder sobre los entes con las fatales consecuencias lógicas de este acto. Bajo esta luz, el humanismo se ofrece como cómplice natural de todo horror posible que haya podido ser perpetrado en nombre del provecho humano. Aun en la trágica titanomaquia de mediados de siglo entre bolchevismo, fascismo y americanismo, se alzan -en la visión de Heidegger- nada más que tres variantes del mismo poder antropocéntrico y tres candidaturas en lucha por un dominio mundial embellecido de humanitarismo, con lo cual el fascismo bailaba en la cuerda floja, porque dejaba ver más abiertamente que sus adversarios su desprecio por los valores moderados de la paz y la formación cultural. En realidad, el fascismo es la metafísica de la inmoderación, y quizás también una forma inmoderada de la metafísica. Para Heidegger, el fascismo era la síntesis del humanismo y del bestialismo, es decir, la coincidencia paradojal de inhibición y desinhibición". SLOTERDIJK, Peter, Reglas para el Parque Humano, Ediciones Siruela, Madrid, 2000 
específica. Si se quisiera todavía, a pesar de las protestas de Heidegger, hablar otra vez de modo antropológico, se podría definir a los hombres de tiempos históricos como animales, de los cuales unos saben leer y escribir, y otros no. De aquí en adelante hay sólo un paso -aunque de enormes consecuencias- hasta la tesis de que los hombres son animales, de los cuales unos crían y disciplinan a sus semejantes, mientras que los otros son criados: un pensamiento que desde las reflexiones platónicas sobre la educación y el Estado.

En la conferencia Sloterdijk realiza un recorrido panorámico por la tradición occidental, en el que destacan nítidamente cuatro autores: Cicerón - Heidegger Nietzsche - Platón. No es casual la referencia inicial a Cicerón, en gran medida autor o al menos el más célebre contemporáneo de la 'reacuñación' latina de conceptos fundamentales griegos, y de la configuración definitiva de lo que se entiende por humanismo clásico. El papel de Heidegger en esta historia sería evidentemente el de desvirtuar las pretensiones humanistas de salvaguarda de la barbarie por medio de una tradición de lectura que considera al hombre como un mero animal a domesticar a la vez que lo constituye paradójicamente como Hombre soberano en el contexto de un rearme de la subjetividad y de una toma del poder sobre los entes, aspectos a los que Sloterdijk, se referirá de modo central en "El hombre auto-operable" ${ }^{13}$. A diferencia de este humanismo militante que somete a violencia al mundo y al hombre, y precisamente en el momento de su supuesto hundimiento, Heidegger concibe al ser humano como un ámbito de interpelación del Ser mismo.

Surge de tal modo la pregunta de cómo será posible una sociedad de contemplativos auscultadores del Ser, pero la ausencia de respuesta deja de todos modos en pie la pregunta paralela por la vigencia del humanismo clásico, cuyo hundimiento definitivo Heidegger había ya diagnosticado. La salida de este oscuro callejón epocal parece estar para Sloterdijk en una reflexión profundizada sobre el claro, que, a diferencia de Heidegger, no es considerado aquí como una relación ontológica originaria imposible de ser indagada históricamente. El proyecto es ahora una historia social de la tangibilidad del hombre a partir de la pregunta por el Ser, que incorpore la antropología y la técnica tomándolas como datos para ulteriores interrogaciones y nuevas perplejidades.

Sloterdijk relaciona la idea de claro -como el claro del bosque- con lo que él llama la revolución antropogénica, punto inicial de la aventura de la hominización, un proceso ligado esencialmente con la tecnología y en el que naturaleza e historia se articulan inicialmente de un modo extraño, o más bien, en el que una falla 0 falta en la primera es ocasión de la caída de un elemento marginal, que se convierte así en el soporte de un mundo: de tal modo la filosofía de Heidegger es

$13 \quad$ SLOTERDIJK, Peter, "El hombre operable; Notas sobre el estado ético de la tecnología génica", Conferencia del 19 de mayo de 2000, en el Centro de Estudios Europeos (CES) de la Universidad de Harvard, EE UU. Publicado en 2001 por ARTEFACTO, Buenos Aires,

<http://www.revista-artefacto.com.ar/revista/nota/?p=91> 
insertada en la historia por un recurso a la biología (el discurso evolucionista) y la técnica. Con esta inserción, pretende Sloterdijk desvincularse de la componente teórica del pensamiento de Heidegger y tornarse hacia el ámbito de la praxis, una actividad formadora en última instancia, como veremos, volcada mayormente sobre uno mismo, a la que da el nombre genérico y plural de antropotécnicas.

Como primer exponente del claro y de la vida sedentaria, se encuentra la casa, una especie de seno acogedor que suple y corresponde a aquella falta prematura que presagió por vez primera lo humano: con la casa, el hombre se domesticó a sí mismo luego de la caída, la casa es ocasión a su vez de los primeros impulsos teóricos asociados con la mirada a través de la ventana, agujero que sería a su vez como un claro de la pared. Resuenan en este contexto, y a veces son retomadas explícitamente por Sloterdijk las metáforas pastorales de Heidegger, y su imagen del lenguaje como la casa del Ser. Sólo que una mirada exterior a la casa podría ver en ella un artefacto no ya para la domesticación del hombre, sino para su crianza, la producción de hombres pequeños, tal como pone Nietzsche en boca de su vagabundo, Zaratustra, una mirada exterior que anuncia además el inicio de luchas inevitables entre métodos alternativos para la crianza de los hombres.

En la medida en que la historia técnica da a luz un poder acrecentado, se vuelve forzosa la elección de utilizarlo o no: Es la marca característica de la era técnica y antropotécnica que cada vez más pasen al lado activo o subjetivo de la selección ocurrirá con seguridad en el futuro que el juego se encarará activamente y se formulará un código de las antropotécnicas.

\section{3.- De la carta sobre el humanismo a las antropotecnias y el discurso del pos-thumanismo}

Desde un inicio, con la práctica de la lectura (Lesen) y hasta la llegada de la alfabetización universal, se verificó en las poblaciones humanas una división entre aquellos que sabían leer y aquellos que no. En dicha práctica basó el humanismo su proyecto domesticador, pero pasó por alto algo así como una lectura detrás de la lectura, la (re)lectura exhaustiva y selectiva (Auslesen), a la que Sloterdijk caracteriza como el poder detrás del poder. Se introduce aquí la idea de poder de selección, acrecentado entonces y vuelto explícito por los modernos avances científicos, y quizás también por la caída de la cultura letrada, con lo que la necesidad de asumir dicho poder de selección, delegado siempre hasta ahora a través de coartadas humanistas a lo largo del trayecto civilizatorio que encarna el platonismo, se volvería cada vez más una evidencia insoslayable. Dicho poder de elección tendría en última instancia un objetivo lúdico, asociado con "un sujeto refinado, cooperativo, y con tendencia a jugar consigo mismo", tal como se formula en "El hombre auto-operable", y como vemos se volcaría en gran medida sobre el propio sujeto inserto en una red de relaciones cooperativas, al correr cada vez más en desventaja las relaciones de explotación y dominio del ser humano 
respecto del mundo de los entes y de los otros hombres, o la noción del Hombre soberano, de vigencia bajo la égida humanista. ${ }^{14}$

De tal modo, donde el platonismo y -con ello- el humanismo habían visto un proceso pasivo de domesticación o apaciguamiento (Zähmung) de animales racionales a través de la lectura correcta, a partir de Nietzsche puede advertirse la existencia correlativa de un proceso activo de cría (Züchtung) que permaneció en las sombras, impensado, delegado en última instancia en un grupo de remotos remitentes inspirados que pasaban por fundadores de una tradición, pero que en realidad, según Sloterdijk, enmascaraban una deriva a-subjetiva de milenios.

El fenómeno humanista gana atención hoy sobre todo porque recuerda -aun de modo velado y confuso- que en la alta cultura, los seres humanos son cautivados constantemente y al mismo tiempo por dos fuerzas formativas, que llamaremos influjos inhibitorio y desinhibitorio. El convencimiento de que los seres humanos son "animales bajo influjo" pertenece al credo del humanismo, así como el de que consecuentemente es imprescindible llegar a descubrir el modo correcto de influir sobre ellos. La etiqueta Humanismo recuerda -con falsa inocencia- la perpetua batalla en torno al hombre, que se ratifica como una lucha entre las tendencias bestializantes y las domesticadoras.

Estas indicaciones dejan en claro que con la pregunta-por-el-humanismo se alude a algo más que a la conjetura bucólica de que el acto de leer educa. Aquí se halla en juego una definición del ser humano de cara a su franqueza biológica, y a su ambivalencia moral. Pero por sobre todo, esta pregunta sobre cómo podrá entonces el ser humano convertirse en un ser humano real o verdadero, será formulada a partir de ahora de modo ineludible como una pregunta por los medios, por aquello por cuyo intermedio los seres humanos mismos se orientan y forman hacia lo que pueden ser y llegan a ser. Se trata, como se habrá advertido, de uno de los alcances de la Meditación sobre la técnica, en particular de la sentencia según la cual "El hombre, quiera o no, tiene que hacerse a sí mismo, autofabricarse"15. Para Ortega el hombre es un ser técnico, esto es, 'contra natura', puesto que mientras el animal trabaja para satisfacer sus necesidades, el hombre lo hace en cambio para adquirir una sobrenaturaleza, poniendo a su disposición aquello que, biológicamente hablando, le es por completo superfluo. La técnica es, en sí antropógena, pero no deja por ello de ser un lujo a su alcance, es decir al alcance del hombre que ella misma ha engendrado. Y además un lujo exclusivo del hombre, ya que es la técnica el criterio de demarcación respecto a la animalidad de la que el hombre zoológicamente proviene. Como lo señala Ortega "las necesidades humanas son objetivamente superfluas y sólo se convierten en

14 VÁSQUEZ ROCCA, Adolfo, "Sloterdijk 'Normas para el Parque humano'; De la carta sobre el humanismo a las antropotecnias y el discurso del pos-thumanismo", En Revista Observaciones Filosóficas - No 5 / 2007 | ISSN 0718-3712

<http://www.observacionesfilosoficas.net/petersloterdijkdelasnormas.html> 
necesidades para quien necesita el bienestar y para quien vivir es, esencialmente, vivir bien"16.

El fascismo bailaba en la cuerda floja, porque dejaba ver más abiertamente que sus adversarios su desprecio por los valores moderados de la paz y la formación cultural. En realidad, el fascismo es la metafísica de la inmoderación, y quizás también una forma inmoderada de la metafísica. Para Heidegger, el fascismo era la síntesis del humanismo y del bestialismo, es decir, la coincidencia paradojal de inhibición y desinhibición.

Frente a tan enormes condenas e inversiones ronda de nuevo la pregunta por el fundamento de la domesticación y la educación humana, y si los ontológicos juegos pastoriles de Heidegger -que ya en su tiempo sonaron raros y chocantesparecen hoy algo del todo anacrónico, conservan al menos el mérito, a pesar de su precariedad y su torpe carácter inusitado, de haber articulado la pregunta de la época: ¿qué puede domesticar aún hoy al hombre, si el humanismo naufraga en tanto que escuela domesticadora humana? ¿Qué puede aún domesticar al hombre, si hasta el día de hoy sus esfuerzos de automoderación lo han llevado en gran medida precisamente a su toma del poder sobre todo ente? ¿Qué puede domesticar al hombre si hasta aquí en todos los experimentos de educación de la especie humana quedó poco claro hacia quién o hacia qué educaban los educadores? ¿O no habrá que dejar de lado definitivamente la idea de una formulación competente de la pregunta sobre el cuidado y formación del hombre en el marco de la mera domesticación?

La polémica ha seguido propagándose en parte por la reconocida agresividad de los términos "ganaderos" utilizados por Sloterdijk, que en Alemania suscitan siniestros recuerdos eugenésicos, pero en parte también por una coincidencia temporal de la que Sloterdijk era seguramente consciente: la era de la información parece haberse completado muy recientemente con la era de la biotecnología, con los alimentos transgénicos, la fecundación artificial y la elaboración del "mapa" del genoma humano, con la clonación de animales y quizá, en un futuro próximo, con la "repetición" -programada- de seres humanos.

La sospecha de Nietzsche contra toda cultura humanística irrumpe para revelar el secreto de la domesticación de la humanidad. Quiere nombrar por su nombre a los hasta hoy detentadores del monopolio de la crianza -el sacerdote y el maestro, que se presentan a sí mismos como amigos del hombre-, revelar su función silenciosa, y desencadenar una lucha, nueva en la historia mundial, entre diversos programas de crianza y de educación.

Este es el conflicto básico que Nietzsche postula para el futuro: la lucha entre los pequeños criadores y los grandes criadores del hombre -se podría también decir, entre humanistas y superhumanistas, amigos del hombre, y amigos del superhombre. "El emblema del superhombre no representa en las reflexiones de Nietzsche el sueño de una rápida desinhibición o una evasión en lo bestial, como imaginaron los malos lectores con botas de los años '30"17. Tampoco encierra

16 ORTEGA Y GASSET, José, Meditación de la técnica, Espasa - Calpe, Madrid, 1965, p. 28

17 SLOTERDIJK, Peter, Normas para el Parque Humano, Ediciones Siruela, Madrid, 2000 
dicha expresión la idea de una regresión del hombre al estado anterior a las épocas del animal doméstico o el animal de iglesia. Cuando Nietzsche habla de superhombre, es para referirse a una época muy por encima del presente. Él nos da la medida de procesos milenarios anteriores, en los que, gracias a un íntimo entramado de crianza, domesticación y educación, se consumó la producción humana, en un movimiento que por cierto supo hacerse profundamente invisible y que ocultó el proyecto de domesticación que tenía como objeto bajo la máscara de la escuela.

Por debajo del luminoso horizonte de la escolar domesticación humana, Nietzsche -que ha leído con similar atención a Darwin y el apóstol Pablo- cree descubrir un horizonte más sombrío. Barrunta el espacio en que comenzarán pronto inevitables luchas por los derechos de la crianza humana, y en este espacio se muestra el otro rostro, el rostro velado del claro. Cuando Zaratustra cruza la ciudad en la que todo se ha vuelto pequeño, descubre el resultado de una política de buena crianza hasta entonces exitosa e incuestionada: le parece que, con la ayuda de una unión destinada de ética y genética, los hombres se las han arreglado para criarse en su pequeñez. Ellos mismos se han sometido a la domesticación, y han hecho una elección de buena crianza poniéndose en camino hacia una sociabilidad de animales domésticos. De este reconocimiento surge la propia crítica zaratustriana del humanismo como rechazo de la falsa inocencia con que se envuelve el buen hombre moderno. No es de hecho nada inocente que los hombres críen a los hombres en el sentido de la inocencia. La sospecha de Nietzsche contra toda cultura humanística irrumpe para revelar el secreto de la domesticación de la humanidad.

Es la marca característica de la era técnica y antropotécnica que cada vez más pasen al lado activo o subjetivo de la selección, aun sin tener que ser arrastrados al papel de selector de un modo voluntario. Respecto a esto hay que dejar algo en claro: hay un malestar en el poder de elección, y pronto constituirá una opción a favor de la inocencia el hecho de que los hombres se rehúsen explícitamente a ejercitar el poder de selección que han alcanzado de modo fáctico. Pero cuando en un campo se desarrollan positivamente poderes científicos, hacen los hombres una pobre figura en caso de que, como en épocas de una temprana impotencia, quieran colocar una fuerza superior en su lugar, ya fuese el dios, o la casualidad, o los otros. Dado que los rechazos o renuncias suelen naufragar por su propia esterilidad, ocurrirá con seguridad en el futuro que el juego se encarará activamente y se formulará un código de las antropotécnicas. Por su efecto retrospectivo, un código tal cambiaría también el significado del humanismo clásico, pues con él se publicaría y registraría que la 'humanitas' no sólo implica la amistad del hombre con el hombre, sino también -y de modo crecientemente explícito- que el ser humano representa el más alto poder para el ser humano.

\section{4.- Sloterdijk: Heidegger y los pastores del ser. De la matriz bucólica y}




\section{pastoral al "capitalismo cárnico contemporáneo". ${ }^{18}$}

Con el post-humanismo el eje escritura/lectura que articulaba la cultura humanista pierde protagonismo ante la emergencia de nuevos medios de expresión y comunicación. Frente al miedo a que las máquinas terminen sustituyendo a los humanos, el post-humanismo recupera la actitud xenolátrica y se plantea la necesidad de desarrollar un el post-humanismo se constituye como una respuesta filosófica a un mundo donde cada vez es más difícil distinguir entre lo natural y lo artificial (si acaso aún fuera necesario hacer dicha distinción). Un pensamiento ecológico (en su sentido más amplio) que tenga en cuenta no sólo el entorno natural sino también el tecnológico (e incorpore, entre otras cosas, los derechos cívicos de las máquinas). Según Sloterdijk hay que prescindir de una interpretación (humanista) del mundo estructurada sobre la dicotomía sujetoobjeto, porque "los hombres necesitan relacionarse entre ellos pero también con las máquinas, los animales, las plantas, (...) y deben aprender a tener una relación polivalente con el entorno" 19.

La historia de esta cohabitación con elementos cuyo estatuto ontológico no ha sido suficientemente aclarado es, como se ha señalado, el desafío de la filosofía de Sloterdijk. Bajo esta perspectiva, el mismo el hombre aparece como una deriva biotecnológica asubjetiva.20 De allí la crisis del humanismo y el reclamo por parte de Sloterdijk de una nueva constitución ontológica que tenga en cuenta a los otros seres humanos, a los animales y las máquinas, esto - planteado en "Normas para el Parque humano"- suscitará las ásperas controversias con Habermas, disputa semi-velada en torno a las posibilidades tecnológico-genéticas de mejora del ser humano. Este debate no ha sido sino la secularización posmetafísica del viejo problema del Humanismo, a saber el de la domesticación del ser humano.

En cualquier caso Sloterdijk, si bien adopta una posición crítica frente al humanismo, prefiere hablar de pensamiento trans-humanístico o post-humanístico y considera la expresión "anti-humanismo" como una "necia formulación que sugiere una forma metafísica de misantropía ${ }^{21}$.

18 VÁSQUEZ ROCCA, Adolfo, "Sloterdijk y Heidegger: Normas para el Parque ZoológicoTemático Humano, Culturas Post-Humanísticas y Capitalismo Cárnico Contemporáneo", En NÓMADAS, Revista Crítica de Ciencias Sociales y Jurídicas - Universidad Complutense de Madrid

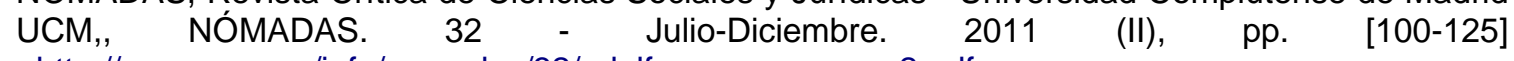
<http://www.ucm.es/info/nomadas/32/adolfovasquezrocca_2.pdf>

19 SLOTERDIJK, Peter, "El post-humanismo: sus fuentes teológicas, sus medios técnicos", Conferencia pronunciada en el IV Seminario: 'La deshumanización del mundo. Estancias de reflexión en torno a la crisis del humanismo', celebrado entre el 6 y 9 de Mayo de 2003 en la Universidad Internacional de Andalucía (UNIA), Sevilla. / En Revista Observaciones Filosóficas, 2005 <http://www.observacionesfilosoficas.net/posthumanismo.html>

${ }_{20}$ VÁSQUEZ ROCCA, Adolfo, Peter Sloterdijk; Esferas, helada cósmica y políticas de climatización, Colección Novatores, № 28, Editorial de la Institución Alfons el Magnànim (IAM), Valencia, España, 2008.

${ }_{21}$ VÁSQUEZ ROCCA, Adolfo, "Sloterdijk y Heidegger: Humanismo, deshumanización y posthumanismo en el Parque Humano", En NÓMADAS, Revista Crítica de Ciencias Sociales y Jurídicas - Universidad Complutense de Madrid, No 23 | Julio-Diciembre.2009 (I) pp. 303-317. 
Para contextualizar la historia de la polémica sobre la vigencia del humanismo es necesario tener en cuenta la influencia ejercida por movimientos filosóficos anteriores, prestando especial atención a la obra de Nietzsche que ha desempeñado un papel clave en la reflexión del pensamiento contemporáneo en torno al asunto de los últimos hombres22.

Sloterdijk señala en "Normas para el Parque Humano" que "los hombres de ser un simple rebaño conducido y guiado por pastores privilegiados, (...) Los pueblos nómadas y ganaderos se transformaron después de muchos siglos en pueblos agrícolas". Sloterdijk intenta dilucidar a qué refiere Heidegger con "los pastores del ser", ya que si bien las formulaciones pastoriles de la carta sobre el Humanismo son bien conocidas, no se ha precisado el sentido de estas figuras, antes bien han sido objeto de burlas soterradas.

Adentrándose en estas formulaciones heideggerianas, Sloterdijk también interrogará por ¿quiénes son los visitantes y qué significa ser vecino de esta extraña abstracción, a la cual se le denomina el Ser?

En primer término, resulta evidente que el discurso pastoral de Heidegger es eminentemente ético, dado que por medio de él se exige una forma particular de contención, recogimiento, modestia, escucha, preparación, podría incluso hablarse de un catálogo de virtudes ontológicas secundarias. Aquí se percibe la exhortación a comportarse como las cinco "vírgenes prudentes" del Evangelio de $\mathrm{Mateo}^{23}$, que portan sus lámparas encendidas hasta que llega la hora de que aparezca el novio. La disposición a la llamada del ser es todo.

La amonestación fundamental es la de mantener una atenta y diligente disposición a la llamada del ser (lo que en Heidegger lo es todo). El ser ha caído en olvido, pero Heidegger empecinadamente quiere seguir intentando ponernos a la escucha de la "llamada del ser". "Estar a la escucha es siempre estar a orillas del sentido o en un sentido de borde y extremidad" ${ }^{24}$ - como si el sonido no fuese justamente otra cosa que ese borde, esa franja o ese margen-. Y parece que esa llamada Heidegger cree escucharla en la Poesía que es la fundación del ser por la palabra (Holderlin). Heidegger cree encontrar en el poeta un documento preontológico (en el sentido de Ser y tiempo) de lo que reflexiona el filósofo como "claro" o "luminidad" (Lichtung), el horizonte luminoso del sentido del ser. "En ese lugar situado, que es el lugar que en otros textos llama "lo abierto", el ser se da, (se le da a Heidegger) es un don. Pero ese lugar, "lo entre", espacio-intersección entre dioses y hombres, es ahora un lugar deshabitado en los tiempos de escasez y necesidad de los que se lamentaba el poeta, un lugar despoblado de dioses. Los dioses han huido de los hombres, pero nos dejaron sus huellas ${ }^{25}$. Los signos de

${ }_{22}$ http://www.ucm.es/info/nomadas/23/avrocca2.pdf

Lo que Nietzsche tenía ante los ojos, en su visión de los últimos hombres era la elevación maníaca de la mediocridad autosatisfecha y semidepresiva. Los últimos hombres habrían de celebran el abaratamiento del hombre mediante los hombres como su realización.

23 Mateo 25: 2 - 9, Santa Biblia, versión Reina Valera de 1909.

$24 \quad$ NANCY, Jean-Luc, A la Escucha, Amorrortu, Editores Buenos Aires, 2007 p. 20

25 MANZANO, Julia, "Metafísica Perennis. Un escrito con y contra Heidegger; El ser como luz y don o como dictado", En Taula (UIB) núm. 13-14, 1990, Barcelona . 
esas huellas las detectan los poetas y las transforman en canto. El poeta es "el cantor del ser", nos dice Heidegger. En la experiencia religiosa se ofrece la posibilidad al poeta, al intermediario entre dioses y hombres, de acceso al ser. Tal experiencia es gratuita, es un don. Pero un don que quizás muy pocos hombres reciban (si nos atenemos a la doctrina alemana protestante acerca de la predestinación ${ }^{26}$ ).

Para Sloterdijk, Heidegger es el último metafísico de la vieja Europa, porque su pensamiento permanece totalmente vinculado al paradigma de un mundo en crecimiento tal y como es experimentado por un campesino. La concepción de un mundo en crecimiento comporta las ideas de productividad y progreso. Pero ¿de qué producto y progreso se trata? El producto en cuestión es aquí, ante todo, el hombre mismo, y el progreso, su cometido de guardar el Ser y corresponderle como su pastor. Lo que hay en juego en todo esto, es la expresión de un problema antiquísimo, a saber, el de la cría y domesticación del hombre por el hombre; un problema en el que han estado involucrados, por referirse sólo al gremio, todos los filósofos, y que podría denominarse como la disputa por la antropogénesis, esto es, la lucha encarnizada por obtener un derecho procreador y tutorial sobre el hombre $^{27}$. Es en razón del intento heideggereano de dilatar el imaginario de la era agraria del mundo que se puede barruntar el porqué de la aversión de Heidegger hacia el humanismo y la técnica. Se trataba de la crisis de la paternidad y del principio genealógico de la especie o de la criatura hombre.

Heidegger, haciendo gala de la aguda perspicacia del reaccionario, advierte la sociedad de la democracia liberal y capitalista como el fin de la comunidad en torno a la tierra. En este sentido la afirmación de Sloterdijk según la cual "Heidegger es el último cerebro de la era agraria", trae consigo la concepción de la política clásica de acuerdo a la cual los hombres eran obras de hombres gestados en el seno de la comunidad, a la vez que unidos a la tierra por un cordón umbilical llamado tradición. "En este proceso histórico de conservación del hombre por el hombre, la metafórica agraria concebía a cada nueva generación de hombres como el producto del orden y rotación inmemorial de siembras y cosechas" ${ }^{28}$. Hoy ya no hay escenarios para el pastoreo. El individualismo occidental contemporáneo ya no comulga con concepciones gregarias.

Mediante la técnica las generaciones en proceso de gestación tienden a elevar sus niveles de lujo y confort. La técnica sería el único elemento de traspaso que ha perdurado con una continuidad ascendente desde el surgimiento de las culturas superiores, hace cuatro o cinco mil años, hasta hoy. Sin embargo, en opinión de Sloterdijk, la labor humana de mayor relevancia, y no sólo por su factura técnica, se forjó en el período más antiguo y nebuloso de la especie,

\footnotetext{
26 DIERKEN, Jörg : GLAUBE UND LEHRE IM MODERNEN PROTESTANTISMUS. Studien zum Verhältnis von religiösem Vollzug und theologischer Bestimmtheit bei Barth und Bultmann sowie Hegel und Schleiermacher. Mohr-Siebeck, Tübingen, 1996.

27 VÁSQUEZ ROCCA, Adolfo, Peter Sloterdijk; Esferas, helada cósmica y políticas de climatización, Colección Novatores, No 28, Editorial de la Institución Alfons el Magnànim (IAM), Valencia, España, 2008, p. 105

$28 \quad$ Ibid. p. 106
}

(c) EMUI Euro-Mediterranean University Institute | Universidad Complutense de Madrid | ISSN 1578-6730 Publicación asociada a la Revista Nomads. Mediterranean Perspectives | ISSN 1889-7231 
específicamente, en la milenaria vida de las hordas, momento en el que se hace posible por primera vez la generación de hombres por parte de hombres, a saber, la antropogénesis. A este gesto grupal y psicosocial de la horda, Sloterdijk lo califica como paleopolítica, esto es, "el milagro de la repetición del hombre por el hombre" ${ }^{29}$. La antropogénesis sería, entonces, el legado más antiguo de toda tradición humana, y quizás también la función primordial a la que estuvo, alguna vez, ordenado el legado completo de la técnica.

Ahora bien, el interés de Sloterdijk por el planteamiento de Heidegger se origina particularmente por las formulaciones pastorales por las que la carta sobre el humanismo es bien conocida, y eso a pesar de todos aquellos que se burlan de ellas. Ahora bien, ¿qué son los pastores del ser? ¿Quiénes son los vigilantes, y qué significa ser vecino de esa extraña abstracción (el Ser)?

Pero con esta ética de la contención ocurre algo muy particular. La comprensión heideggeriana del ser pastoral se nutre con toda seguridad de dos fuentes: de entrada, de la imagen del buen pastor cristiano, que hace lo que sea por sus ovejas, y también, por otro lado, de varias metáforas bucólico-campesinas del muchacho guardián. Ambas dimensiones tienen que ver con funciones relativamente ajenas al poderío y la técnica, habida cuenta de que el pastor de Heidegger, este punto es muy importante, no es realmente alguien con capacidad de hacer esto o lo otro; su única facultad reside en que sabe estar bien atento y se da cuenta de lo que pasa en el rebaño. Una parte de la magia de las metáforas heideggerianas radica en que identifican una aparente inacción, un vigilar en guardia, con una posibilidad suprema de ser-ahí.

¿Qué hacen, pues, los pastores heideggerianos? Están despiertos, esto es, contribuyen a que el mundo pueda ser mundo, y nada más. Aquí subyace la intuición espiritual de que lo poco es mucho, mientras que lo mucho no es casi nada si los presupuestos son falsos. No es nada mientras el polihacedor sólo siga siendo un furibundo durmiente que nunca despierta de su hipnosis activista ${ }^{30}$.

A estas indicaciones heideggerianas, procedentes de la tradición de la sabiduría y que, de nuevo, se extinguen en su seno, he añadido una observación que modifica su imagen idílica de vigilancia ${ }^{31}$. Digo así que en el claro no moran sólo pastores silenciosos y vigilantes desasidos. También hay otras figuras, no tan buenos pastores en su tarea, de los que en realidad también ha de hablarse. Se necesita acceder al conocimiento de que existen dos pastorales radicalmente diferentes: una idílica y otra inquietante, hablando en términos e historia de la cultura: una campesina y otra relativa al nomadismo ganadero. En un breve artículo titulado

29 REYES, Carlos, "La concepción político-antropológica de Peter Sloterdijk; La horda como útero social y el arte de caminar juntos", En Revista Observaciones Filosóficas N N 7 / 2008. [Análisis del Texto En el mismo barco Ensayo sobre hiperpolítica. Esbozo de la Tesis de Magister desarrollada por el autor en el Instituto de Filosofía PUCV bajo la dirección del Dr. Adolfo Vásquez Rocca.

<http://www.observacionesfilosoficas.net/laconcepcionpoliticaantropologica.htm>

30 SLOTERDIJK, Peter y HEINRICHS, Hans-Jürgen, El sol y la muerte; Investigaciones dialógicas, Siruela, Madrid, 2004, pp. 129 y sgtes.

lbid., p. 130 
"Lust auf Fleisch?”32 [“¿Placer de la carne?”], Thomas Macho ha llamado la atención con agudeza sobre esta diferencia, insuficientemente percibida hasta ahora, introduciendo en su obra un nuevo paradigma filosófico en el ámbito de la historia cultural. De aquí puede aprenderse que hay un pastoreo bueno y otro malo, el que en el ámbito agrario guarda el ganado y el que cría de manera nómada el ganado. Ahora bien, mientras que Heidegger, como puede comprobarse fácilmente permanece ligado a la semántica campesina y cristiana del buen pastor, yo me permito recordar la imagen del pastoreo nómada y de los pastores malos e inquietantes, aunque seguramente de una forma extremadamente lacónica. También aquí nos las tenemos que ver con un texto subyacente que necesita ser explicitado.

Para la tradición pastoral agraria hay buenas razones para definir la conjunción de pastor y animal bajo el signo de desasimiento [Gelassenheit], por tanto es un ser ajeno a la técnica y abierto a lo presente. En todo caso, este pastor tiene que cuidar de que ningún animal se descarríe. Así se ha conservado esta imagen dentro de la tradición cristiana, incluso yendo más lejos, hasta el extremo de que el buen pastor se sacrifica por sus ovejas. Algo muy distinto ocurre en el tipo de nomadismo pastoral: éste especula con la posibilidad de establecer procesos de reproducción sobre su rebaño, y por una razón que se deja revelar con facilidad: él quiere justamente lo que en principio no puede tener en un recinto, en concreto, tenerlo y comérselo. A la luz de su diseño civilizatorio, los pastores son carnívoros; ellos, por consiguiente, no sólo guardan sus rebaños, sino que también los vigilan y dirigen su reproducción a gran escala, de tal suerte que no cesan de conservar excedentes animales para el consumo. Ciertamente, estos pastores no portan el emblema del desasimiento como tal, sino el emblema de la producción, esto es, de la exportación animal, like it or not. Como puede comprenderse, son criadores y, eo ipso, biotécnicos en una escala muy simple, manipulan los procesos vitales con todas sus consecuencias. Si se observa esto con más detenimiento, puede reconocerse que, en el otro lado, la existencia campesina en absoluto actúa en los procesos vitales con una actitud de cuidado ajeno a la técnica, sino que también en ella las manipulaciones vitales desempeñan una función decisiva, aunque sea más bien respecto al mundo vegetal ${ }^{33}$.

Por todo ello, en el claro está en juego algo más que un mero vigilar silenciosos de lo que está ahí de suyo. La vigilancia en el claro es más que el cuidado de una apertura. Nada distinto expresó Sloterdijk en Basilea en su comentario respecto a la problemática del cuidado de lo humano en manos de los hombres. Resulta

\footnotetext{
32 MACHO,Thomas, “Lust auf Fleisch?” Kulturhistorische Überlegungen zu einem ambivalenten Genuß, in: Jahrbuch 1999/2000 des Wissenschaftszentrums Nordrhein-Westfalen, Düsseldorf (Wissenschaftszentrum Nordrhein-Westfalen) 2000, 140-157; sowie in: Dirk Matejovski/Dietmar Kamper/Gerd-C. Weniger (Hrsg.): Mythos Neanderthal. Ursprung und Zeitenwende, Frankfurt/ Main/New York (Campus) 2001, 147-162; sowie in: Gerhard Neumann/ Alois Wierlacher/Rainer Wild (Hrsg.): Essen und Lebensqualität. Natur- und kulturhistorische Perspektiven, Frankfurt/Main/New York (Campus) 2001, 157-174.

33 SLOTERDIJK, Peter y HEINRICHS, Hans-Jürgen, El sol y la muerte; Investigaciones dialógicas, Siruela, Madrid, 2004, p. 131
} 
indiferente saber si aquí actúan campesinos o culturas dedicadas a la cría de ganado, lo cierto es que aquí, en ambas formas, se encuentra dada de antemano una cierta prototécnica para la intervención en procesos vitales. Criar animales y plantas significa distribuir de manera desigual oportunidades para reproducir, por tanto organizar y preferir, distinguir y subyugar según criterios establecidos en función de la utilidad humana. En este contexto se puede comprender qué enorme conflicto transcurre a través del mundo moderno, a saber: el conflicto existente entre los protectores de la vida y los exploradores de vida, expresado en tipos: el conflicto afincado entre el habitus campesino y el nómada.

El dilema ético de los hombres modernos radica en el hecho de que piensan como vegetarianos y viven como carnívoros. Ésta es la razón de que, en nosotros, la ética y la técnica nunca corran en dirección paralela. Queremos ser tan buenos como los buenos pastores, pero al mismo tiempo vivir tan bien como los malos pastores, famosos por sus fiestas violentas y su dañina vida disipada. Este dualismo tiene como efecto que todos los debates actuales sobre ética posean un cierto regusto de falsedad. Cuando habla, el hombre moderno se encuentra escindido: es un nómada con piel de cordero o un malvado pastor bajo el ropaje de una buena persona. Cuando uno se topa en la actualidad con la alabanza intelectual cada vez más popular del nómada, habría que pensar que, actuando así, se rehabilita en última instancia el modo de ser del pastoreo nómada; nadie debería creer que éste es un discurso inofensivo. A efectos de acercarnos más a este tema, podría ser de utilidad releer un libro de Jeremy Rifkin, Das Imperium der Rinder ${ }^{34}$ ["El imperio de los terneros"] (1994), en el que su posición era entonces más clara que ahora. En esta obra el monstruoso paralelismo existente entre la historia humana y la historia de la cría de ganado al por mayor es desarrollado hasta llegar a su punto culminante en el capitalismo cárnico contemporáneo.

\section{5.- Constitución inmunitaria de la naturaleza humana; antropotecnias y presagios sobre los últimos hombres.}

En su más reciente libro, Has de cambiar tu vida ${ }^{35}$, Sloterdijk aborda la historia de los procesos inmunológicos espirituales desde las antiguas tradiciones filosóficas

\footnotetext{
$34 \quad$ Kapitel 1 aus "Das Imperium der Rinder" von Jeremy Rifkin, 1994. RIFKIN, Jeremy, Das Imperium der Rinder. Campus-Verlag, Frankfurt / New York 1994, Frankfurt 1997, ISBN 3-59613606-7. Una obra de Jeremy Rifkin, El imperio de los terneros, en donde observa el monstruoso paralelismo entre la historia humana y el de la cría de ganado al por mayor, hasta desembocar en el capitalismo cárnico actual.

35 SLOTERDIJK, Peter, (2009) Has de cambiar tu vida; sobre Antropotécnica, Editorial PreTextos, Valencia, 2012

Un libro aparecido en este año (2012), cuyo nombre nace de un poema de Rilke a partir del Apolo de Rodin en el Louvre, nos pone de frente ante las tradiciones ascéticas de oriente y occidente: ¿pueden haber respuestas a la actual crisis global desde esos ejercicios ascéticos? Leerlo es como conversar con un viejo sabio de voz pausada y profunda.
} 
de oriente y occidente hasta internarse en las modernas tecnologías génicas ${ }^{36}$. Sloterdijk en la primera parte de la obra nos pone de frente ante las tradiciones ascéticas de oriente y occidente: ¿pueden haber respuestas a la actual crisis global desde esos ejercicios ascéticos? Leerlo es como conversar con un viejo sabio de voz pausada y profunda. Retomado - ya hacia el final del escrito algunas cuestiones esbozadas en "El hombre operable; Notas sobre el estado ético de la tecnología génica" ${ }^{37}$, del que me he hecho cargo en el Artículo "Sloterdijk y Nietzsche; Nihilismo, antropogénesis y presagios sobre los últimos hombres". ${ }^{38}$

¿Desde qué luz mirar nuestras decisiones espirituales como seres humanos que cruzamos calles, escampamos de la lluvia o nos refugiamos en nuestras casas? ¿Hacia dónde nos refugiamos? ¿De quién o de qué? ¿Cómo enfrentamos los miedos? Nuestros acercamientos al arte, a la educación, al deporte, a las religiones, ¿qué pueden significar? Ya sea el arte, la religión o los deportes requieren de nosotros un comportamiento ascético, una disciplina, un refrenamiento de las pasiones. ${ }^{39}$

El movimiento que aquí se dice que se despliega lo califica Würtz, consecuentemente, no como una mera compensación, sino como una supercompensación: en él, la reacción iría más allá del impulso inicial ${ }^{40}$.

Alli donde aparezca el ser humano, le antecede su estatus de impedido: ése era el estribillo de los discursos filosóficos sobre el hombre en el siglo pasado, independientemente de que se hable, como lo hace el psicoanálisis, del ser humano como de un mutilado falto de ayuda, que sólo puede llegar a sus metas renqueando, ${ }^{41}$ o de que se le considere, como hacen Bolk y Gehlen, un lisiado neoténico- cuya inmadurez crónica sólo es compensable mediante rígidas envolturas culturales- , o como hace Plessner, un discapacitado excéntrico, que está al margen de si mismo y se ve a sí mismo viviendo, o bien, como hacen Sartre y Blumenberg, un discapacitado de la visibilidad, condenado de por vida a entender la desventaja de ser visto por otros. ${ }^{42}$

$36 \quad$ Retomado algunas cuestiones esbozadas por Sloterdijk en "El hombre operable; Notas sobre el estado ético de la tecnología génica" (2000), Artículo que además de traducir he comentado en el Artículo: "Sloterdijk y Nietzsche; Nihilismo, antropogénesis y presagios sobre los últimos hombres" publicado en PSIKEBA, Revista de Psicoanálisis y Estudios Culturales, de la Universidad de Buenos Aires (UBA), ISSN 1850-339X, Nº 8, 2008.

$37 \quad$ SLOTERDIJK, Peter, "El hombre operable;Notas sobre el estado ético de la tecnología génica, Conferencia tuvo lugar el 19 de mayo de 2000, En Revista Observaciones Filosóficas, Traducción propia.

38 VÁSQUEZ ROCCA, Adolfo, "Sloterdijk y Nietzsche; Nihilismo, antropogénesis y presagios sobre los últimos hombres" publicado en PSIKEBA, Revista de Psicoanálisis y Estudios Culturales, de la Universidad de Buenos Aires (UBA), ISSN 1850-339X, No 8, 2008.

39 CASADIEGO, Benjamin , Recensión de Has de cambiar tu vida de Peter Sloterdijk, julio de 2012 -Publicado por La red Departamental de Bibliotecas del Cesar.

$40 \quad$ SLOTERDIJK, Peter, Has de cambiar tu vida. Sobre antropotécnica, Editorial Pre-Textos, Valencia, 2012, p. 83

41 SCHENEIDER, Peter, Erhinken und erfliegen. Psychoanalytische Zwifel an der Vernunft, Gotinga, 2001.

42 SLOTERDIJK, Peter, Has de cambiar tu vida. Sobre antropotécnica, Editorial Pre-Textos, Valencia, 2012, p. 83 
Aquí nuevamente encontramos a Sloterdijk en medio de una polémica o cuestionamiento filosófico de largo alcance. He aquí la nueva polémica: entre las mayores influencias que recibe Sloterdijk para resolver las cuestiones recién planteadas se encuentra la del sociólogo y filósofo Arnold Gehlen, ${ }^{43}$ figura non sancta en Alemania por haber sido miembro del Partido Nacionalsocialista y luego un crítico acervo del movimiento estudiantil del 68. En escritos tales como El hombre: su naturaleza y su lugar en el mundo ${ }^{44}$, de 1940, y El hombre en la era de la tecnología, de $1957^{45}$, Gehlen desarrolla la célebre tesis del hombre como Mängelwesen, como "ser deficitario". Parte del supuesto de que el hombre es un ser orgánicamente "desvalido", es decir que no está dotado por la naturaleza con órganos especializados capaces de adaptarse al medio ambiente. No tiene, como otros animales, órganos de ataque, de defensa o de huida. No está revestido de pelaje ni preparado para la intemperie, carece de alas para volar, etc. Frente a esta "falta de especialización" orgánica, el animal hombre se ve obligado, para sobrevivir, a devenir un "ser cultural". Lo cual significa que ante la imposibilidad orgánica de adaptarse al medio ambiente, debe crear un medio ambiente artificial que le permite producirse a sí mismo con relativa independencia del mundo orgánico. Así, pues, siendo el hombre un ser carencial por naturaleza, incapaz de adaptarse a ningún ambiente natural, debe fabricarse una "segunda naturaleza", un mundo artificial sustitutivo que compense su deficiente equipamiento orgánico (Gehlen 1993).

Es en este punto donde la técnica cumple un papel fundamental. En vista de su constitución biológica, el hombre no podría conservarse dentro de la naturaleza tal como ésta es, de primera mano, sino que se ve abocado a emprender una modificación práctica de cualquier realidad natural con la que se encuentra. El concepto Techné es utilizado por Gehlen para indicar la destreza, la competencia, el entrenamiento y la habilidad alcanzados por los hombres para construir una "naturaleza segunda", una "sobrenaturaleza", como la llamaba Ortega y Gasset ${ }^{46}$.

$43 \quad$ Arnold Gehlen: filósofo y sociólogo alemán, miembro del partido nazi. Sus teorías han inspirado el desarrollo del neoconservadurismo contemporáneo alemán. Sus mayores influencias como estudiante de filosofía fueron Hans Driesch, Nicolai Hartmann y, especialmente, Max Scheler. Se unió en 1933 al partido Nazi, y tuvo una brillante carrera como miembro de la escuela de Leipzig, bajo la tutela de Hans Freyer. Reemplazó a Paul Tillich, quien había emigrado a Estados Unidos, en la Universidad de Frankfurt. Desde su puesto de profesor, Gehlen criticó los movimientos de protesta desarrollados en la última parte de la década de los años 1960. La filosofía de Gehlen fue una fuerte influencia para muchos pensadores alemanes neoconservadores contemporáneos. Conceptos de su obra, como Reizüberflutung o "sobreabundancia de estímulos", y desinistitucionalización (post-historia o fin de la historia), véase Kojève, Jünger, Adorno, han ganado amplio consenso en Alemania. En 1938 aceptó el cargo de profesor en la Universidad de Königsberg y en 1940 en la Universidad de Viena, en donde enseñó hasta ser llamado a filas por la Wehrmacht en 1943.

$44 \quad$ GEHLEN, Arnold, Título original en alemán: Der Mensch. Seine Natur und seine Stellung in der Welt.

${ }_{45} \quad$ Para vivir en regiones heladas, por ejemplo, el hombre primitivo carecía ciertamente de dotación natural, pero pudo calentarse con fuego y envolverse en pieles de las que él mismo carecía. Sin embargo, ello supuso el desarrollo de una techné que le permitió generar habi-lidades para cazar animales más grandes, producir artificialmente fuego y fabricar herramientas especiales.

Ortega y Gasset ya se había pronunciado en términos muy similares en su Meditación de 
No es posible para el hombre sobrevivir sin la ejercitación organizada y metódica que le permita operar con eficiencia en contra de la naturaleza interna y externa. Sin el desarrollo de una serie de prácticas coordinadas y disciplinadas, sin la pericia y la especialización, el animal humano habría sido barrido fácilmente por el devenir de una naturaleza hostil para la que no estaba preparado (Gehlen). ${ }^{47} \mathrm{La}$ técnica, en este caso, no son las herramientas que el hombre fabrica, sino el conjunto de acciones coordinadas, estratégicas, reglamentadas y orientadas al logro de una finalidad precisa. Podríamos decir que la técnica es producto de la inteligencia práctica del hombre, aquella que le permite "disponer" del entorno y someter-lo a sus necesidades vitales. No es, entonces, que el hombre haga "uso" de la técnica, sino que el hombre es, en sí mismo, un animal técnico. La técnica no es algo agregativo sino constitutivo del animal humano. O para decirlo de otro modo: a consecuencia de su infradotación orgánica, el hombre se ve abocado a pensar y actuar técnicamente. $Y$ es esta habilidad compensatoria lo que le permitió devenir "Homo sapiens" (Gehlen). ${ }^{48}$

\section{6.- Inmunología especulativa, medicina romántica y ontología de la enfermedad.}

Una de las prácticas antropotécnicas descritas por Sloterdijk en "El hombre operable" es la de dejarse tratar, una práctica biomédica. La cultura del dejar-sehacer-algo -Sloterdijk la caracteriza a partir de la figura del cliente, en el área de la medicina aparece una forma de pasividad más antigua, para la que, tradicionalmente, se ha reservado la expresión de "paciente". ${ }^{49}$ No debiera extrañarnos que en el curso del siglo XXI dicha expresión esté en extinción del vocabulario médico, lo que esta en marcha es la clientización de los servicios y prestaciones. Lo anterior es concomitante con la creciente juridización de la relación médico-paciente. Sin embargo, independientemente de cómo se designe la relación entre el médico y el "paciente", el hecho relevante en términos antropotécnicos se produce cuando este último se confía al primero con motivo de

la Técnica. Para él: el hombre, merced a su don técnico, hace que se encuentre siempre en su derredor lo que ha menester -crea, pues, una circunstancia nueva más favorable, segrega, por decirlo así, una sobrenaturaleza adaptando la naturaleza a sus necesidades .

Y a continuación mantenía una tesis fundamental para reflexionar sobre la tecnología: la técnica es lo contrario de la adaptación del sujeto al medio, puesto que es la adaptación del medio al sujeto. Ya esto bastaría para hacernos sospechar que se trata de un movimiento en dirección inversa a todos los biológicos .

Para vivir en regiones heladas, por ejemplo, el hombre primitivo carecía ciertamente de dotación natural, pero pudo calentarse con fuego y envolverse en pieles de las que él mismo carecía. Sin embargo, ello supuso el desarrollo de una techné que le permitió generar habilidades para cazar animales más grandes, producir artificialmente fuego y fabricar herramientas especiales.

48 GEHLEN, Arnold, Antropología filosófica. Del encuentro y descubrimiento del hombre por sí mismo. Barcelona: Paidós, 1993.

Ibid, p. 481 
una intervención quirúrgica. $Y$ entonces se habla, en sentido convencional, de dejarse operar, queriendo decir que en virtud de un diagnóstico serio, el paciente tiene que estar dispuesto a someterse a un tratamiento invasivo. Lo que el léxico médico articula bajo la formula vulnerando sanamus ("sanamos hiriendo") y que tiene su traducción, del lado del paciente, en la hipótesis: al dejarme herir por manos competentes hago un servicio a mi curación. Aunque el desnivel entre el rol del paciente y del que opera en él se hace aquí más profundo no cabe duda de que, indirectamente, el paciente también actúa, complementando con ello este espacio autooperativo.

La encorvadura se redondea hasta convertirse en un círculo completo cuando el operador externo es el operado, una rara excepción, que no obstante está documentada en la historia de la medicina. Un ejemplo destacado de ello lo ofrece el médico L. Rogozov, el cual se vio obligado a operarse a sí mismo por una apendicitis durante su estancia en la estación de investigación rusa Nowalezarewskaya en la Antártica, en 1961. Una foto famosa nos lo muestra yaciendo en una mesa con vestimenta quirúrgica y una mascarilla protectora en la cara, mientras se abre la parte inferior derecha del vientre.

Por lo general, la retroacción autooperativa sobre uno mismo, gracias a la cual el sujeto tolera modificaciones técnicas de su cuerpo, revela una encorvadura más superficial. Se articula, aproximadamente desde el siglo XVIII, en el uso extensivo que el europeo ilustrado hace de sustancias estimulantes. Su uso se incrementa desde el siglo $\mathrm{XX}$ en un despliegue masivo de medios de doping en todas las disciplinas posibles. Es sabido hasta qué grado autores como Voltaire o Balzac eran adictos a la cafeína, así como cuánto debía Sigmund Freud a la cocaína. Tampoco es ningún secreto, para quienes conocen sus últimos años, a qué extremos llevaron a Sartre sus fluctuaciones entre el alcoholismo y el anfetaminismo. En todos estos casos lo importante es, evidentemente, qué hicieron los así estimulados con lo que los estimulantes habían hecho de ellos. La adicción de Sartre a las anfetaminas no dejaba de ser algo irónico, al hacerse dependiente de un medio que debía darle la sensación de una total independencia.

Sloterdijk elaborará una descripción de las potencias plásticas que producen lo humano, lo que implica una concepción fuerte de la idea de esfera antropogenética que integra lo político. Este modo de abordar la potencia plástica antropogenética acerca Sloterdijk a la biopolítica afirmativa tal como la han desarrollado en los últimos años todos aquellos que han seguido la estela del pensamiento de Deleuze. Esta concepción de lo biopolítico basada en un monismo del afecto y llevada incluso a interrogarse sobre las condiciones moleculares del ejercicio del poder, se aleja sensiblemente del análisis del biopoder desarrollado por Foucault y Agamben.

Cuando Sloterdijk habla de "experimentos con uno mismo", no piensa en un experimento de vivisección en las propias carnes, ni tampoco en la psicosis romántica del psicoanálisis francés ${ }^{50}$. Con esta expresión Sloterdijk hace 
referencia, más bien, a un fenómeno perteneciente a la historia de la medicina moderna, el movimiento homeopático, que remonta Hahnemann, quien hace más de doscientos años ${ }^{51}$ formuló por primera vez el principio del remedio terapéutico efectivo. Asimismo, él fue uno de los primeros curadores en tratar el nerviosismo moderno de sus pacientes con propuestas médicas adecuadas. Estaba convencido de que el médico estaba obligado a intoxicarse a sí mismo con todo lo que él más tarde iba a prescribir a los enfermos. De esta reflexión procede el concepto de experimento con uno mismo: quien quiera ser médico necesita previamente ser cobaya.

La razón más honda de esta transformación encaminada a la experimentación con el propio cuerpo hay que encontrarla en la idea romántica de la relación activa entre la imagen y el ser. Hahnemann consideraba que los efectos de las dosis en el hombre sano y el enfermo se reflejaban de manera especular. Es aquí donde se origina una ambiciosa semiótica de la medicación farmacológica. El gran pensamiento optimista de la medicina romántica pertenece esencialmente a la homeopatía; es más, reside en el hecho de que hay que presumir una relación de reflejo entre lo que es la enfermedad como fenómeno global y los efectos que un medio puro provoca en el cuerpo sano. La homeopatía piensa en el plano de una inmunología especulativa. $Y$ en la medida en que los problemas inmunológicos son considerados cada vez más aspectos prioritarios de la terapéutica y la sistemática del futuro, hemos de vérnoslas aquí con una tradición muy actual, por mucho que el funcionamiento de las dosis homeopáticas siga envuelto en un velo de oscuridad.

Sloterdijk se refiere a un proceso similar en Experimentos con uno mismo ${ }^{52}$ una suerte de tratado de intoxicación voluntaria en referencia al creador de la homeopatía, Samuel Hahnemann, como inventor de una micropolítica de la subjetividad. De la misma manera que el homeópata, según Hahnemann, debe intoxicarse a sí mismo antes de poder dar consejo alguno, el teórico político debe estar dispuesto a arriesgar su identidad en la práctica.

\section{7.- Experimentos con uno mismo, autointoxicación y metáforas homeopáticas.}

Sloterdijk se refiere a un proceso similar en Experimentos con uno mismo ${ }^{53}$ una suerte de tratado de intoxicación voluntaria en referencia al creador de la homeopatía, Samuel Hahnemann, como inventor de una micropolítica de la subjetividad. De la misma manera que el homeópata, según Hahnemann, debe intoxicarse a sí mismo antes de poder dar consejo alguno, el teórico político debe estar dispuesto a arriesgar su identidad en la práctica.

\footnotetext{
dialógicas, Editorial Siruela, Madrid, 2004, p. 12

$51 \quad$ En el año 1796.

52 SLOTERDIJK, Peter, Experimentos con uno mismo, Editorial Pre-Textos, Valencia, 2003.

53 SLOTERDIJK, Peter, Experimentos con uno mismo, Editorial Pre-Textos, Valencia, 2003.
} 
En Sloterdijk se trata de la intoxicación voluntaria en los problemas de la época, de la cual dice que puede surgir la figura del diagnóstico, del lamento poético o de la creación literaria. Quizás, como bien propone la investigadora Margarita A. C. Martínez: "toda su obra se pueda leer bajo el signo del diagnóstico, desde Crítica de la razón cínica ${ }^{54}$ hasta su más reciente trilogía Esferas. En todos estos textos, in crescendo, la lengua de Peter Sloterdijk avanza pronto hacia una lengua maníaca, azuzada por los matices técnicos de la época, una lengua polémica. Una de las expresiones más acabadas de este estilo filosófico es efectivamente Esferas $^{55}$, donde Sloterdijk se lanza a una indagación fenomenológica del espacio que se cruza por primera vez, en el eje de una larga historia, con la dimensión política. Esta indagación fenomenológica, bajo el precepto de la autointoxicación, parte de sumergirse en la cultura técnica contemporánea, para luego extraer síntomas en aras de una redefinición de lo humano. En este caso, nos vamos a detener en el diagnóstico que Sloterdijk realiza respecto del hombre y la técnica en la época actual a partir de la noción de artificio como viraje dentro del humanismo occidental; de eso se trata un breve texto titulado 'La vejación a través de las máquinas'". ${ }^{56}$

No puede resultar extraño que este discurso encuentre afinidades con el de Nietzsche, quien en no pocas ocasiones jugó con metáforas homeopáticas o, más aún, inmunológicas. No es ninguna casualidad que él pusiera en boca de Zaratustra y en presencia de la multitud la frase: "Os inoculo la locura"57 Y eso por no hacer mención a su ominosa sentencia "Lo que no me mata me hace más fuerte" ${ }^{\prime 58}$, una expresión que hay que entender a todas luces en un sentido inmunoteórico. Nietzsche comprendía su vida toda como una suerte de inoculación de sustancias tóxicas de decadencia, y trató a su vez de organizar su existencia como una reacción integral de inmunización. No fue capaz de darse por satisfecho con esa ingenuidad blindada de los últimos hombres gracias a lo cual estos se protegían de las infecciones de sus contemporáneos y de la historia. De ahí que que estas reflexiones de Sloterdijk puedan insertarse más bien dentro de la corriente de la filosofía naturalista romántica; dicho más concretamente, tiene más que ver con la metafísica alemana de la enfermedad que con el discurso francés en torno al cuerpo desmembrado.

En la historia del pensamiento moderno - de Marx a Nietzsche- la política y la clínica corren en paralelo- en medio de fantasmas sanitarios y metáforas farmacológicas. Sloterdijk aduce al respecto que un autor (investigador) tiene la obligación de pensar peligrosamente. El escritor no está para contraer

54 SLOTERDIJK, Peter, (1983) Crítica de la razón cínica, Editorial Siruela -Biblioteca de Ensayo / Serie mayor, Serie Mayor. 23-, Madrid, 5a Edición, 2011.

55 SLOTERDIJK, Peter, Esferas I. Burbujas, Ediciones Siruela, Madrid, 2003

56 MARTÍNEZ, Margarita, "La vejación a través de las máquinas. El concepto de artificio en Peter Sloterdijk", En Revista iberoamericana de ciencia tecnología y sociedad, Buenos Aires, Vol.5, No.14 pp. 125-132. Disponible en:

<http://www.scielo.org.ar/scielo.php?script=sci_arttext\&pid=S185000132010000100009\&lng=es\&nrm=iso>

57 NIETZSCHE. Friedrich, (1883) Así habló Zaratustra, 1992. Citado por Sloterdijk en El Sol y la Muerte (2001), p. 13, Ediciones Siruela, 2004

$58 \quad$ NIETZSCHE. Friedrich, El Crepúsculo de los ídolos, Alianza Editorial, Madrid, 1997, p. 30 
compromisos con la inocuidad. Los autores importantes son sobre todo los que piensan en arriesgarse. De ahí que su filosofía experimental presuponga algo más que una simple comprensión metafórica de la homeopatía. El estar-infectado, esa participación casi psicosomática en las dolencias de la propia época. ${ }^{59}$ El escritor, continúa, no está para contraer compromisos con la inocuidad. Los autores importantes son sobre todo los que piensan en arriesgarse.

Si bien el origen de la medicina homeopática se remonta hasta el mismo Hipócrates, no fue hasta que el médico alemán Samuel Hahnemann (Dressen, Alemania. 1755-1843) descubrió que la corteza de un árbol de Perú -el quinoproducía en las personas sanas los síntomas de la malaria, pero proporcionaba enormes beneficios en la recuperación de los pacientes que sufrían esa terrible enfermedad, con lo cual comenzó a popularizarse esta medicina alternativa. De hecho, la homeopatía se basa en el principio "similia similibus curantur" que se traduce en "lo similar se cura con lo similar. En otras palabras, es un método terapéutico que se fundamenta en la ley de los semejantes o ley de la similitud mediante el cual se aplica a las enfermedades dosis mínimas de aquellas sustancias que, en cantidades mayores, producirían en el hombre sano síntomas iguales o parecidos a los que se tratan de combatir para que, de esta manera, se estimule al sistema inmunológico del organismo para que luche contra la enfermedad. Este es el mismo pensamiento que sirvió de base para las vacunas descubiertas por Edward Jenner y Louis Pasteur las cuales provocan una reacción en el individuo que protege contra la enfermedad. Los tratamientos de alergias trabajan, igualmente, de esta manera al exponer a una persona a cantidades del alergeno.

Samuel Hahnemann; este espíritu asombroso es el primero en haber formulado, hace exactamente doscientos años, el principio del medicamento efectivo. Es el primero en haber respondido a la impaciencia moderna de los pacientes, esa clientela burguesa de la salud, con una oferta médica adecuada, aislando productos puros a fin de conocer su verdadero efecto. Él pensaba que era indispensable que un médico se infectara a sí mismo y se hombres gracias a lo cual éstos se protegían de las infecciones de sus contemporáneos y de la historia administrara todo lo que más tarde daría a sus pacientes. Y esto porque los efectos de una dosis en un enfermo y en alguien de buena salud están invertidos como en un espejo. Una semiótica medicamentosa radical nace al mismo tiempo que una sintomatología de las enfermedades. La gran idea optimista de la medicina romántica, de la cual forma parte la homeopatía, se caracteriza por una suerte de isomorfismo, una relación en espejo, una reciprocidad de lo que es la enfermedad como entidad fenoménica y lo que un médico provoca en el sujeto sano. En este sentido, el enunciado de la tesis pertenece más bien a la tradición de la filosofía romántica de la naturaleza, es decir, a la filosofía romántica de la enfermedad y la salud; del mismo modo, pertenece a la tradición nietzscheana el uso de metáforas homeopáticas. Como ha señalado Nietzsche: "Los inoculo contra la locura" ${ }^{\prime 60}$, desarrollando así maravillosamente, a partir de ese momento, NIETZSCHE. Friedrich, Así habló Zaratustra. Edición Original 1883. 
la representación crítica de una salud hacia la muerte, de un caparazón patológico contra las infecciones de la época contemporánea.

Es así que de Hahnemann a Nietzsche se suceden una serie de metáforas y máximas homeopáticas, que pueden conducir a un particular tipo de curación y efectos terapéuticos. Aquí se pone de manifiesto un aspecto particularmente importante: ese estar-infectado, esa participación casi psicosomática en las dolencias de la propia época.

"Un autor es un laboratorio para piezas más complejas, para ideas poco practicadas. Su interior sirve como un espacio experimental en el que se testan y malean materias temáticas especialmente virulentas, entre ellas, sustancias de alto contenido tóxico. Existe una relación directa entre la grandeza de un autor y la peligrosidad de las materias temáticas que procesa y domina. De lo inofensivo sólo brota lo inofensivo, de lo peligroso brota el pensamiento, y cuando el pensamiento encuentra el punto exacto de la forma, surge el momento artístico."61

El autor valioso y útil es el que se contamina él mismo con las materias con las que trabaja, sustancias de alto contenido tóxico, este planteamiento no ha cambiado. Kafka, Musil, Broch, Burroughs, todos los grandes del siglo XX, también han sido maestros del pensamiento peligroso.

- Doctor en Filosofía por la Pontificia Universidad Católica de Valparaíso; Postgrado Universidad Complutense de Madrid, Departamento de Filosofía IV, mención Filosofía Contemporánea y Estética. Profesor Asociado de la Escuela de Psicología UNAB y al Grupo Theoria -Proyecto europeo de Investigaciones de Postgrado- UCM. Académico Investigador de la Vicerrectoría de Investigación y Postgrado, Universidad Andrés Bello. -Investigador Asociado de la Escuela Matríztica de Santiago dirigida por el Dr. Humberto Maturana. Consultor Experto del Consejo Nacional de Innovación para la Competitividad (CNIC). Ha publicado: Peter Sloterdijk; Esferas, helada cósmica y políticas de climatización, Colección Novatores, $\mathrm{N}^{\circ} 28$, Editorial de la Institución Alfons el Magnànim (IAM), Valencia, España, 2008. Invitado especial a la International Conference de la Trienal de Arquitectura de Lisboa | Lisbon Architecture Triennale 2011, Conferencias Traducidas al Francés compendiadas en Architecture de la Anthologie: Le Néant Dans la Pensée Contemporaine. Publications du Centre Français d'Iconologie Comparée CFIC, Bès Editions , París, 2012 , Director de Revista Observaciones Filosóficas. Eastern Mediterranean University - Academia.edu

61 SLOTERDIJK, Peter, Experimentos con uno mismo. Una conversación con Carlos Oliveira. Valencia: Pre-Textos, 2003 


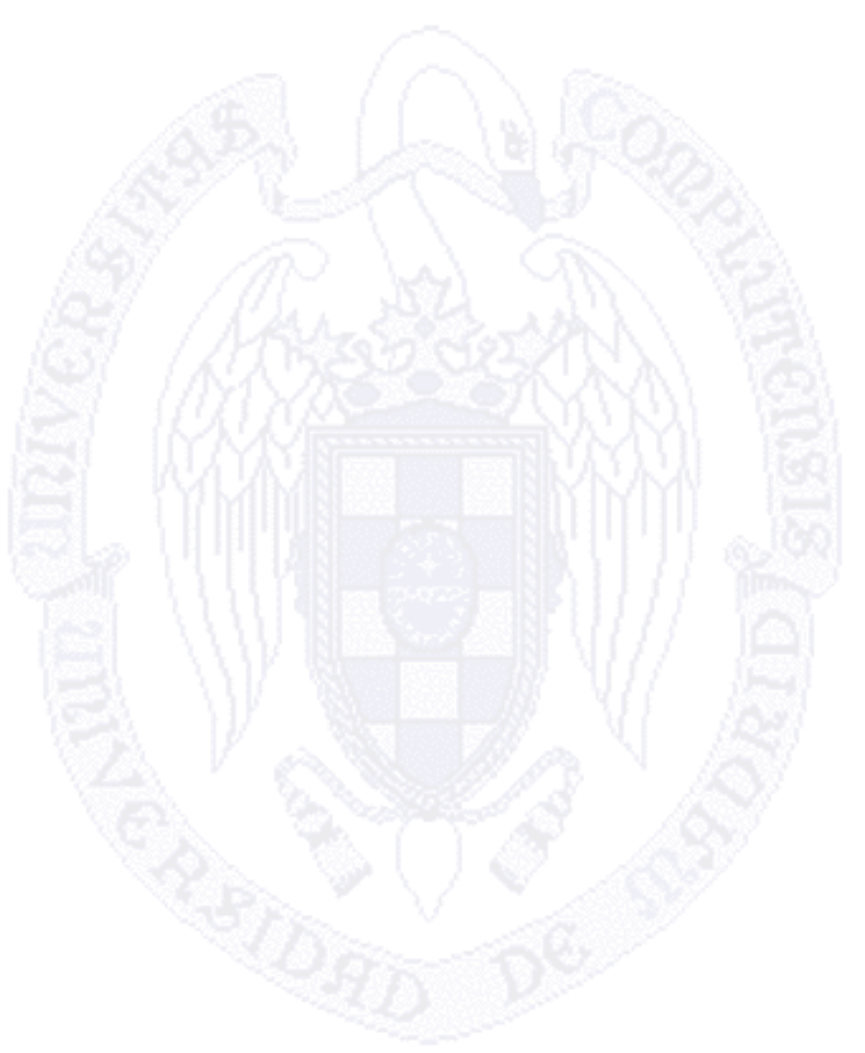




\section{BIBLIOGRAFÍA}

SLOTERDIJK, Peter. (2000) Normas para el Parque Humano, una respuesta a la Carta sobre el humanismo, Madrid, Ediciones Siruela, 2008

SLOTERDIJK, Peter y HEINRICHS, Hans-Jürgen, El sol y la muerte; Investigaciones dialógicas, Siruela, Madrid, 2004

SLOTERDIJK, Peter - FINKIELKRAUT, Alain, Los Latidos del Mundo. Diálogo; (Trad. de la ed. en frances Heber Cardoso); Buenos Aires; Amorrrortu; 2008 [publicada en alemán en 2004. COAUTOR Alain Finkielkraut]

SLOTERDIJK, Peter, Extrañamiento del Mundo; (trad. Eduardo Gil Bera); Valencia; Pre-Textos; 1998 [publicada en alemán en 1993]

SLOTERDIJK, Peter, (2001) Sin salvación. Tras las huellas de Heidegger, Akal, Madrid, 2011

M.: Suhrkamp, 2001

SLOTERDIJK, Peter, Esferas I. Burbujas, Ediciones Siruela, Madrid, 2003

SLOTERDIJK, Peter, Esferas II, Globos, Macroesferología, Ediciones Siruela, Madrid,. 2004

SLOTERDIJK, Peter, Esferas III, Espumas, Editorial Siruela, Madrid, 2005.

SLOTERDIJK, Peter, "El hombre operable; Notas sobre el estado ético de la tecnología génica", Conferencia del 19 de mayo de 2000, en el Centro de Estudios Europeos (CES) de la Universidad de Harvard, EE UU. Publicado en 2001 por ARTEFACTO, Buenos Aires, <http://www.revistaartefacto.com.ar/revista/nota/?p=91>

SLOTERDIJK, Peter, (2009) Has de cambiar tu vida; sobre Antropotécnica, Editorial Pre-Textos, Valencia, 2012

SLOTERDIJK, Peter, Experimentos con uno mismo. Una conversación con Carlos Olivera, Editorial Pre-Textos, Valencia, 2003

HEIDEGER, Martin, Carta sobre el Humanismo, Traducción de Helena Cortés y Arturo Leyte, Alianza Editorial, Madrid, 2000

NIETZSCHE. Friedrich, El Crepúsculo de los ídolos, Alianza Editorial, Madrid, 1997 
- NIETZSCHE, Friedrich, (1883) Así habló Zaratustra, Madrid, Alianza Editorial, 1992

NANCY, Jean-Luc, A la Escucha, Amorrortu, Editores Buenos Aires, 2007

- CORDUA, Carla, Sloterdijk y Heidegger; La recepción filosófica, Santiago, Ediciones Universidad Diego Portales, 2008

- DUQUE, Felix, En torno al humanismo. Heidegger, Gadamer, Sloterdijk, Editorial Tecnos, Madrid, 2002

VÁSQUEZ ROCCA, Adolfo, Peter Sloterdijk; Esferas, helada cósmica y políticas de climatización, Colección Novatores, № 28, Editorial de la Institución Alfons el Magnànim (IAM), Valencia, España, 2008

1996

DERY, M., Escape Velocity. Cyberculture at End of the Century, New York, Valencia, 1999

J. M. NAVARRO CORDÓN y R. RODRÍGUEZ (Comp.), "Heidegger o el final de la filosofía", Editorial Complutense, Madrid, 1997

MACHO,Thomas, "Lust auf Fleisch?" Kulturhistorische Überlegungen zu einem ambivalenten Genuß, in: Jahrbuch 1999/2000 des Wissenschaftszentrums Nordrhein-Westfalen, Düsseldorf (Wissenschaftszentrum Nordrhein-Westfalen) 2000

- PUCCIARELLI, Eugenio, Los rostros del humanismo. Banco Boston, Buenos Aires, 1987

DIERKEN, Jörg: Glaube und Lehre im Modernen Protestantismus. Studien zum Verhältnis von religiösem Vollzug und theologischer Bestimmtheit bei Barth und Bultmann sowie Hegel und Schleiermacher. Mohr-Siebeck, Tübingen, 1996. Madrid, 1965.

ORTEGA Y GASSET, José, Meditación de la técnica, Espasa - Calpe,

SIBILIA, Paula, El hombre postorgánico: cuerpo, subjetividad y tecnologías digitales. Fondo de Cultura Económica, Buenos Aires, 2005.

HAILES, K. N., How We Becaume Posthuman. Virtual Bodies in Cybernetic, Literatura, and Information, Chicago- London 1999.

DIETER CLAESSENS. Das Konkrete und das Abstrakte. Soziologische Skizzen zur Anthropologie. Frankfurt am Main, 1985. 
- HARAWAY, D., Cyborg and Women: The Reinvention of Nature, New York, 1991. Trad. castellana: Manifiesto para cyborgs, Episteme, Valencia, 1995 2002

MARCHESINI, R., Post-human. Verso nuevo modelli di esistenza, Turín,

OLSON, E. T., The Human Animal. Personal Identity without Psychology, NewYork 1997. Trad. It L'animale umano. Identità e continuità biologica, Milán 1999

STUART SIM, Lyotard, y lo inhumano, Editorial Gedisa, Barcelona, 2004

SCHENEIDER, Peter, Erhinken und erfliegen. Psychoanalytische Zwifel an der Vernunft, Gotinga, 2001.

GEHLEN, Arnold, Antropología filosófica. Del encuentro y descubrimiento del hombre por sí mismo. Barcelona: Paidós, 1993.

GEHLEN, Arnold, Título original en alemán: Der Mensch. Seine Natur und seine Stellung in der Welt.

\section{ARTículos}

VÁSQUEZ ROCCA, Adolfo, "Sloterdijk, Habermas y Heidegger; Humanismo, posthumanismo y debate en torno al Parque Humano", En EIKASIA, Revista de Filosofía, No 26 - 2009, ISSN 1885-5679 - Oviedo, España, pp. 11-22 $<$ http://www.revistadefilosofia.com/26-01.pdf>

ASSHEUER, Thomas, "Das Zarathustra-Projekt: Der Philosoph Peter Sloterdijk fordert eine gentechnische Revision der Menschheit", en DIE ZEIT, Ausgabe 36 - 1999-

ASSHEUER, Thomas, "El proyecto Zaratustra. El filósofo Peter Sloterdijk reclama una revisión genético-técnica de la humanidad", En Pensamiento de los confines No 8 (julio de 2000); y Revista de Occidente, ISSN 0034-8635, No 228, 2000.

VÁSQUEZ ROCCA, Adolfo, "Sloterdijk y Canetti; El detonante iconográfico y operístico de la política de masas", en NÓMADAS Revista Crítica de Ciencias Sociales y Jurídicas. Universidad Complutense de Madrid, | No 15 | Enero-Junio 2007, pp. 201-214

http://www.ucm.es/info/nomadas/15/avrocca_detonanteiconografico.pdf

VÁSQUEZ ROCCA, Adolfo, "Sloterdijk, Agamben y Nietzsche: Biopolítica, posthumanismo y Biopoder" En NÓMADAS, Revista Crítica de Ciencias Sociales y 
Jurídicas - Universidad Complutense de Madrid, No 23 | Julio-Diciembre.2009 (I) pp. 291-302. http://www.ucm.es/info/nomadas/23/avrocca.pdf

VÁSQUEZ ROCCA, Adolfo, "Peter Sloterdijk: Normas y disturbios en el parque humano o la crisis del humanismo como utopía y escuela de domesticación", En UNIVERSITAS @ Revista de Filosofía, Derecho y Política, No 8, 2008, pp. 105-119. Universidad Carlos III de Madrid. http://universitas.idhbc.es/n08/08-06.pdf

SLOTERDIJK, Peter, "El post-humanismo: sus fuentes teológicas, sus medios técnicos", Conferencia pronunciada en el IV Seminario: 'La deshumanización del mundo. Estancias de reflexión en torno a la crisis del humanismo', celebrado entre el 6 y 9 de Mayo de 2003 en la Universidad Internacional de Andalucía (UNIA), Sevilla. I En Revista Observaciones Filosóficas, 2005 <http://www.observacionesfilosoficas.net/posthumanismo.html>

MANZANO, Julia, "Metafísica Perennis. Un escrito con y contra Heidegger; El ser como luz y don o como dictado" , En Taula (UIB) núm. 13-14, 1990, Barcelona.

LINK, Daniel, "Hacia las biopolíticas. Ante la ley, el campo de concentración como paradigma de la modernidad", En RAMONA, Revista de Artes Visuales, Buenos Aires, No 14. julio de 2001

REYES, Carlos, "La concepción político-antropológica de Peter Sloterdijk; La horda como útero social y el arte de caminar juntos", En Revista Observaciones Filosóficas $N^{0} 7$ / 2008. [Análisis del Texto En el mismo barco Ensayo sobre hiperpolítica. Esbozo de la Tesis de Magister desarrollada por el autor en el Instituto de Filosofía PUCV bajo la dirección del Dr. Adolfo Vásquez Rocca.

<http://www.observacionesfilosoficas.net/laconcepcionpoliticaantropologica.htm>

MANZANO, Julia, "Metafísica Perennis . Un escrito con y contra Heidegger; El ser como luz y don o como dictado" , En Taula (UIB) núm. 13-14, 1990, Barcelona .

FATTORE, Natalia, "Padre Padrone. Sugerencias para una lectura desde la problemática de la autoridad", Premio Espiral de Edublogs, 2007.

RODRÍGUEZ, Pablo Esteban, “¿Tiene sentido hablar de poshumanismo? Acerca de la relación entre teoría de la comunicación y biopolítica de la información", En Revista Galáxia, São Paulo, n. 20, p. 9-21, dez. 2010.

- DIERKEN, Jörg : GLAUBE UND LEHRE IM MODERNEN PROTESTANTISMUS. Studien zum Verhältnis von religiösem Vollzug und theologischer Bestimmtheit bei Barth und Bultmann sowie Hegel und Schleiermacher. Mohr-Siebeck, Tübingen, 1996. 
TRÍAS, Eugenio, "La razón comisarial", Diario El País, Madrid, domingo 6 de noviembre de 2011.

MARTÍNEZ, Margarita, "La vejación a través de las máquinas. El concepto de artificio en Peter Sloterdijk", En Revista iberoamericana de ciencia tecnología y sociedad, Buenos Aires, Vol.5, №.14 pp. 125-132.

VÁSQUEZ ROCCA, Adolfo, "Sloterdijk y Heidegger: Humanismo, deshumanización y posthumanismo en el Parque Humano", En NÓMADAS, Revista Crítica de Ciencias Sociales y Jurídicas - Universidad Complutense de $\begin{array}{llllll}\text { Madrid, } \quad N^{\circ} & 23 \quad \text { Julio-Diciembre.2009 } & \text { (I) } & \text { pp. 303-317. }\end{array}$ http://www.ucm.es/info/nomadas/23/avrocca2.pdf

VÁSQUEZ ROCCA, Adolfo, "Sloterdijk y Heidegger: Normas para el Parque Zoológico-Temático Humano, Culturas Post-Humanísticas y Capitalismo Cárnico Contemporáneo", En NÓMADAS, Revista Crítica de Ciencias Sociales y Jurídicas - Universidad Complutense de Madrid UCM,, NÓMADAS. 32 - Julio$\begin{array}{llll}\text { Diciembre. } & 2011 & \text { (II), pp. }\end{array}$ <http://www.ucm.es/info/nomadas/32/adolfovasquezrocca_2.pdf>

VÁSQUEZ ROCCA, Adolfo, "Sloterdijk, Heidegger y Jean-Luc Nancy: Esferas, arqueología de lo íntimo, morfología del espacio compartido e historia de la fascinación de proximidad", En NÓMADAS, Revista Crítica de Ciencias Sociales y Jurídicas - Universidad Complutense de Madrid, NÓMADAS. 32 - JulioDiciembre. 2011 (II), pp. [100-139]

<http://www.ucm.es/info/nomadas/32/adolfovasquezrocca.pdf>

VÁSQUEZ ROCCA, Adolfo, "Peter Sloterdijk: Normas y disturbios en el Parque Humano o la crisis del humanismo como utopía y escuela de domesticación", En UNIVERSITAS (c) Revista de Filosofía, Derecho y Política, No 8, 2008, pp. 105-119. Universidad Carlos III de Madrid. <http://universitas.idhbc.es/n08/08-06.pdf>

VÁSQUEZ ROCCA, Adolfo, "William Burroughs: Literatura ectoplasmoide y mutaciones antropológicas. Del virus del lenguaje a la psicotopografía del texto", En Nómadas, Revista Crítica de Ciencias Sociales y Jurídicas - Universidad Complutense de Madrid, NÓMADAS No 26 | Enero-Junio.2010 (II), pp. 251-265. <http://www.ucm.es/info/nomadas/26/avrocca2.pdf>

VÁSQUEZ ROCCA, Adolfo, "Peter Sloterdijk: Normas y Disturbios en el Parque Humano o la crisis del Humanismo como utopía y escuela de domesticación", En NÓMADAS, Revista Crítica de Ciencias Sociales y Jurídicas Universidad Complutense de Madrid, $\mathrm{N}^{\mathrm{O}} 19-2008$ (I), pp. 293-308, <http://www.ucm.es/info/nomadas/19/avrocca.pdf $\geq$ 